\title{
FAME-C: cloud property retrieval using synergistic AATSR and MERIS observations
}

\author{
C. K. Carbajal Henken, R. Lindstrot, R. Preusker, and J. Fischer \\ Institute for Space Sciences, Freie Universität Berlin (FUB), Berlin, Germany \\ Correspondence to: C. K. Carbajal Henken (cintia.carbajal@wew.fu-berlin.de)
}

Received: 29 April 2014 - Published in Atmos. Meas. Tech. Discuss.: 19 May 2014

Revised: 17 September 2014 - Accepted: 11 October 2014 - Published: 25 November 2014

\begin{abstract}
A newly developed daytime cloud property retrieval algorithm, FAME-C (Freie Universität Berlin AATSR MERIS Cloud), is presented. Synergistic observations from the Advanced Along-Track Scanning Radiometer (AATSR) and the Medium Resolution Imaging Spectrometer (MERIS), both mounted on the polar-orbiting Environmental Satellite (Envisat), are used for cloud screening. For cloudy pixels two main steps are carried out in a sequential form. First, a cloud optical and microphysical property retrieval is performed using an AATSR near-infrared and visible channel. Cloud phase, cloud optical thickness, and effective radius are retrieved, and subsequently cloud water path is computed. Second, two cloud top height products are retrieved based on independent techniques. For cloud top temperature, measurements in the AATSR infrared channels are used, while for cloud top pressure, measurements in the MERIS oxygenA absorption channel are used. Results from the cloud optical and microphysical property retrieval serve as input for the two cloud top height retrievals. Introduced here are the AATSR and MERIS forward models and auxiliary data needed in FAME-C. Also, the optimal estimation method, which provides uncertainty estimates of the retrieved property on a pixel basis, is presented. Within the frame of the European Space Agency (ESA) Climate Change Initiative (CCI) project, the first global cloud property retrievals have been conducted for the years 2007-2009. For this time period, verification efforts are presented, comparing, for four selected regions around the globe, FAME-C cloud optical and microphysical properties to cloud optical and microphysical properties derived from measurements of the Moderate Resolution Imaging Spectroradiometer (MODIS) on the Terra satellite. The results show a reasonable agreement between the cloud optical and microphysical property re-
\end{abstract}

trievals. Biases are generally smallest for marine stratocumulus clouds: $-0.28,0.41 \mu \mathrm{m}$ and $-0.18 \mathrm{~g} \mathrm{~m}^{-2}$ for cloud optical thickness, effective radius and cloud water path, respectively. This is also true for the root-mean-square deviation. Furthermore, both cloud top height products are compared to cloud top heights derived from ground-based cloud radars located at several Atmospheric Radiation Measurement (ARM) sites. FAME-C mostly shows an underestimation of cloud top heights when compared to radar observations. The lowest bias of $-0.3 \mathrm{~km}$ is found for AATSR cloud top heights for single-layer clouds, while the highest bias of $-3.0 \mathrm{~km}$ is found for AATSR cloud top heights for multilayer clouds. Variability is low for MERIS cloud top heights for low-level clouds, and high for MERIS cloud top heights for mid-level and high-level single-layer clouds, as well as for both AATSR and MERIS cloud top heights for multilayer clouds.

\section{Introduction}

In the Earth's present climate system, clouds play a key role through their strong interaction with solar radiation and thermal radiation emitted by the Earth's surface and atmosphere, as well as their dominant role in the hydrological cycle. On average about $70 \%$ (Stubenrauch et al., 2013) of the Earth's surface is covered by clouds and their temporal and spatial variability is high. Climate models are used to improve our understanding of regional and global climate and to project future climate changes. However, low confidence is given to the representation and quantification of cloud processes in these models, especially in combination with aerosol processes. Cloud adjustments due to aerosols still contribute 
the largest uncertainty to the total radiative forcing estimate (IPCC, 2013).

Accurate observations of cloud properties on a global scale are needed for climate model development and evaluation, as well as for climate research. Satellite observations provide these global and long-term cloud observations. From observations in the visible, near-infrared and thermal infrared parts of the electromagnetic spectrum, cloud macrophysical properties, such as cloud amount and cloud top height - as well as cloud optical and microphysical properties such as cloud-top thermodynamic phase, cloud optical thickness and effective radius, which describes the cloud particle size distribution can be retrieved.

A number of these types of cloud property retrievals and their accompanying global, long-term cloud data sets exist for a range of multispectral passive imagers on both polarorbiting and geostationary satellites. Several of these data sets are included in the Global Energy and Water Cycle Experiment (GEWEX) Assessment of Global Cloud Datasets from Satellites (Stubenrauch et al., 2013). The objective of this assessment is to evaluate their overall quality. Participating cloud data sets include ATSR-GRAPE, based on observations from the Along-Track Scanning Radiometers (ATSRs) and the Advanced ATSR (AATSR) (Sayer et al., 2011); the International Satellite Cloud Climatology Project (Schiffer and Rossow, 1983), based on observations from imagers on a set of satellites; the Pathfinder Atmospheres Extended (PATMOS-x) (PATMOS-x, 2014), based on observations from the Advanced Very High Resolution Radiometer (AVHRR) on the National Oceanic and Atmospheric Administration (NOAA) satellites, as well as on the Meteorological Operation (MetOp) satellites of the European Organisation for the Exploitation of Meteorological Satellites (EUMETSAT); and cloud products from the MODIS Science Team (NASA, 2014b) and MODIS CERES Science Team (NASA, 2014a), using observations from the Moderate Resolution Imaging Spectroradiometer (MODIS) from the National Aeronautics and Space Administration (NASA) Earth Observing Satellites (EOS) Aqua and Terra. Intercomparisons were performed on monthly mean, gridded cloud data sets. Results show that differences in average cloud properties can arise due to, for example, retrieval filtering, ice-water cloud misidentification, assumptions on cloud particle shape and size distribution, and the set of spectral channels and ancillary data used in the retrievals.

To assess the quality of retrieved cloud properties due to algorithm design itself, i.e., not accounting for instrument design, the Cloud Retrieval Evaluation Workshop (CREW) was initiated by EUMETSAT (Roebeling et al., 2013). Level-2 cloud products derived from a set of well-established cloud property algorithms have been collected and intercompared for predefined days against observations from the active instruments CALIOP (Cloud-Aerosol Lidar with Orthogonal Polarization) onboard CALIPSO (Cloud-Aerosol Lidar and Infrared Pathfinder Satellite Observations), CPR (Cloud Pro- filing Radar) onboard CloudSat, and AMSR-E (Advanced Microwave Scanning Radiometer for EOS) onboard Aqua, all part of the A-train constellation. Participating cloud property algorithms include the CERES (Clouds and Earth's Radiant Energy System) algorithm (Minnis et al., 2011); the DCOMP (Daytime Cloud Optical and Microphysical Properties) algorithm (Walther and Heidinger, 2012), and the CPP (Cloud Physical Properties) algorithm (Roebeling et al., 2006). These kind of studies can reveal strengths and weaknesses for different methods of cloud property retrievals (Hamann et al., 2014) and have shown that large differences can already arise due to different cloud detection methods. This will in turn also affect temporal and spatial averages of cloud properties for climate studies.

In the frame of the European Space Agency (ESA) Climate Change Initiative (CCI) Cloud project (Hollmann et al., 2013), a 10-year daytime cloud climatology of synergistic AATSR and Medium Resolution Imaging Spectrometer (MERIS), both aboard the Environmental Satellite (Envisat), cloud observations is to be produced. The ultimate objective of the project is to provide long-term coherent cloud property data sets for climate research, taking advantage of the synergy of different Earth observation missions. The FAME-C (Freie Universität Berlin AATSR MERIS Cloud) algorithm uses optimal estimation to retrieve a set of daytime cloud properties and their uncertainties on a pixel basis. MERIS and AATSR were not originally designed for cloud observations, but together they provide a useful set of channels in the visible, near-infrared and thermal infrared wavelengths for cloud property retrieval. Furthermore, two independent cloud height products are retrieved: first, using AATSR brightness temperatures from two thermal infrared channels and, second, using the MERIS oxygen-A absorption channel. The follow-up instruments SLSTR (Sea and Land Surface Temperature Radiometer) and OLCI (Ocean Land Colour Instrument) onboard Sentinel-3 (ESA, 2014d), expected to be launched by mid-2015, will have very similar channel settings, making the FAME-C algorithm applicable to their observations as well.

This paper is intended to serve as a reference to the FAME$\mathrm{C}$ algorithm. The structure of the paper is as follows. First, AATSR and MERIS observations are introduced and preprocessing is shortly explained in Sect. 2 . Section 3 presents the forward models used in the cloud optical and microphysical property retrieval, and in both the cloud top temperature retrieval and cloud top pressure retrieval. In addition, a short note on auxiliary data is given. Next, Sect. 4 presents an overview of the retrieval scheme, treating the applied inversion technique and listing uncertainty estimates. Section 5 shows verification results of the comparison of FAME-C level-2 cloud properties with MODIS-Terra cloud optical and microphysical properties and cloud top heights derived from ground-based radar observations. Finally, in Sect. 6, a summary and discussion are given. 


\section{Observation data and preprocessing}

\subsection{Instruments}

AATSR and MERIS are both imaging multispectral radiometers onboard the polar-orbiting satellite Envisat, which was launched in March 2002 and was in operational use until April 2012, providing a 10-year measurement data set. Envisat flies in a Sun-synchronous polar orbit around the Earth at a mean altitude of $800 \mathrm{~km}$ and a $98.5^{\circ}$ inclination. It has a repeat cycle of 35 days and the mean local solar time at descending node is 10:00. The MERIS instrument has 15 spectral channels, which are programmable in position and width within the solar spectral range (400 to $905 \mathrm{~nm}$ ), and scans the Earth by means of a push-broom method. It has a horizontal resolution of just over $1 \mathrm{~km}$ at the subsatellite point and its field of view, resulting in a swath width of $1150 \mathrm{~km}$, is covered using five identical optical cameras. AATSR has spectral channels in the visible part as well as in the nearinfrared and thermal infrared part of the spectrum (channels at $0.55,0.66,0.87,1.6,3.7,11$ and $12 \mu \mathrm{m}$ ). It has a horizontal resolution of $1 \mathrm{~km}$ at subsatellite point and a swath width of $512 \mathrm{~km}$. Due to its conical scanning method, it has a dual view of the Earth's surface for all spectral channels. More details on both instruments can be found in Llewellyn-Jones et al. (2001), Rast et al. (1999) and ESA (2014c).

\subsection{Collocation and cloud screening}

Cloud property retrievals are performed for pixels identified as cloudy by a synergistic cloud mask, which is produced using the cloud-screening module in the BEAM toolbox (Fomferra and Brockmann, 2005; ESA, 2014a). First, the AATSR observations are collocated with MERIS observations on the MERIS grid (reduced resolution mode, $1200 \mathrm{~m} \times 1000 \mathrm{~m}$ ) using a nearest-neighbor technique. This grid was chosen because of MERIS's better geolocation. Then, a cloud screening is performed by combining a set of neural networks optimized for different cloudy situations and using all AATSR and MERIS channels. Finally, the produced synergy product contains all AATSR and MERIS channels as well as the newly produced cloud mask. It should be noted that the synergy product has a swath width of 493 pixels, which is less than the AATSR swath width of 512 pixels. This is related to collocating the curved AATSR grid with the MERIS grid. Technical details on the collocation and cloud-screening method can be found in Gómez-Chova et al. (2008) and Gómez-Chova et al. (2010).

\subsection{Drift and stray light correction}

An improved long-term drift correction is applied to the AATSR reflectances for the visible and near-infrared channels from the second reprocessing as described in Smith et al. (2008). For MERIS measurements, the third reprocessing has been used (ESA, 2011). Furthermore, an empirical stray light correction was applied to the reflectance of the MERIS oxygen-A absorption channel (Lindstrot et al., 2010). For this correction, the spectral smile effect in the MERIS measurements (Bourg et al., 2008), which is the variation of the channel center wavelength along the field of view, as well as the amount of stray light in the MERIS oxygen-A absorption channel, was determined.

\section{Forward model}

\subsection{Cloud optical and microphysical properties}

The retrieval of the cloud optical and microphysical properties cloud optical thickness (COT, $\tau$ ) and effective radius (REF, $r_{\text {eff }}$ ) for water and ice clouds, and subsequently also cloud water path (CWP), is based on the DCOMP algorithm and largely follows the approach as described in Walther and Heidinger (2012). The COT-REF pair is retrieved using simultaneous measurements of the AATSR 0.66 and $1.6 \mu \mathrm{m}$ channels. It is based on the assumption that the reflectance in the visible (VIS) mainly depends on COT due to conservative scattering, while the reflectance in the near-infrared (NIR) mainly depends on the cloud droplet size distribution due to weak absorption. This method is based on work by Nakajima and King (1990) and has since been used in a number of cloud property retrievals (e.g., Nakajima and Nakajma, 1995; Roebeling et al., 2006; Walther and Heidinger, 2012).

Lookup tables (LUTs) for both water and ice clouds consisting of cloud reflectances have been created with simulations from the radiative transfer model MOMO (Matrix Operator Model). MOMO was developed at the Freie Universität Berlin (Fell and Fischer, 2001; Hollstein and Fischer, 2012) and allows for simulations of radiative transfer in a plane-parallel homogeneous scattering medium with any vertical resolution. The cloud reflectance, $R_{\mathrm{c}, \lambda}$, at wavelength $\lambda$ (wavelength dependency will not be used in the text from now on) is given by

$R_{\mathrm{c}, \lambda}=\frac{\pi \cdot L_{\mathrm{c}, \lambda}\left(\theta_{0}, \theta, \phi, \tau, r_{\mathrm{eff}}\right)}{\cos \left(\theta_{0}\right) \cdot F_{0, \lambda}\left(\theta_{0}\right)}$,

where $L_{\mathrm{c}}$ is the radiance reflected by the cloud and $F_{0}$ is the incoming solar irradiance at the top of the atmosphere. The radiance $L_{c}$ is a function of solar zenith angle $\theta_{0}$, viewing zenith angle $\theta$, and relative azimuth angle $\phi$, as well as cloud optical thickness and effective radius. The simulations have been performed assuming a homogeneous cloud and no contribution from the atmosphere as well as the surface, i.e., no gaseous absorption, Rayleigh scattering and aerosol extinction, and zero surface albedo. Then, the reflectance at the cloud top $R_{\text {toc }}^{\prime}$ when including a Lambertian reflecting surface is computed as follows:

$R_{\mathrm{toc}, \lambda}^{\prime}=R_{\mathrm{c}, \lambda}+\frac{\alpha_{\lambda} \cdot t_{\mathrm{c}, \lambda}\left(\theta_{0}, \tau, r_{\mathrm{eff}}\right) \cdot t_{\mathrm{c}, \lambda}\left(\theta, \tau, r_{\mathrm{eff}}\right)}{1-\alpha_{\lambda} \cdot S_{\lambda}\left(\tau, r_{\mathrm{eff}}\right)}$, 
Table 1. Atmospheric correction coefficients for AATSR 0.66 and $1.6 \mu \mathrm{m}$ channels.

\begin{tabular}{lrrr}
\hline & $a_{0}$ & $a_{1}$ & $a_{2}$ \\
\hline $0.66 \mathrm{H}_{2} \mathrm{O}$ & $7.86 \times 10^{-5}$ & $3.9971 \times 10^{-3}$ & $-1.06 \times 10^{-4}$ \\
$0.66 \mathrm{O}_{3}$ & $2.2229 \times 10^{-3}$ & $3.9840 \times 10^{-5}$ & $3.9945 \times 10^{-8}$ \\
$1.6 \mathrm{H}_{2} \mathrm{O}$ & $-2.13 \times 10^{-5}$ & $9.472 \times 10^{-4}$ & $-4.0 \times 10^{-6}$ \\
\hline
\end{tabular}

where $\alpha$ is the surface albedo; $t_{\mathrm{c}}\left(\theta_{0}\right)$ and $t_{\mathrm{c}}(\theta)$ are the cloud transmittance in the downward and upward directions, respectively; and $S$ is the spherical albedo.

To compare the measured reflectances at the top of the atmosphere to the forward model results, which are simulated reflectances without consideration of atmospheric extinction processes, the measured reflectances are corrected for atmospheric extinction of radiation due to gaseous absorption and Rayleigh scattering. Other sources of extinction, e.g., aerosols, are not considered. The top-of-cloud reflectance, $R_{\text {toc }}$, is computed from the measured top-of-atmosphere reflectance, $R_{\mathrm{toa}}$, as follows:

$R_{\mathrm{toc}, \lambda}=\frac{R_{\mathrm{toa}, \lambda}-R_{\mathrm{RS}, \lambda}\left(\theta_{0}, \theta, \phi, \tau, r_{\mathrm{eff}}, p_{\mathrm{c}}\right)}{t_{\mathrm{a}, \lambda}\left(\theta, \theta_{0}\right)}$,

where $R_{\mathrm{RS}}$ is the back-scattered signal due to single scattering events above the cloud (here only Rayleigh scattering in the visible channel is taken into account) and $t_{\mathrm{a}}$ is the two-way atmospheric transmittance above the cloud. The Rayleigh scattering correction is based on Wang and King (1997) and is only performed in the VIS channel. Next to the viewing geometry, it depends on cloud albedo $\alpha_{\mathrm{c}}$, which in turn depends on COT and REF, and Rayleigh optical thickness from cloud top to the top of the atmosphere, $\tau_{\mathrm{r}}$. The Rayleigh optical thickness is determined assuming a total column Rayleigh optical thickness of 0.044 at surface pressure $1013 \mathrm{hPa}$ (Wang and King, 1997) and scaling it by an estimated cloud top pressure $p_{\mathrm{c}}$. The atmospheric transmittance above the cloud is determined considering absorption by water vapor (total column water vapor above cloud) and ozone (total ozone in Dobson units) in the VIS channel and only absorption by water vapor in the NIR channel. A quadratic relationship, and its accompanying coefficients, $a_{i}$, between the amount of absorber gas $M$ (here water vapor or ozone) above cloud and the gas transmittance, $t_{\mathrm{a}}$, also depending on air mass factor (AMF), is determined using a number of MODTRAN simulations. The gas transmission is computed as follows:

$t_{\mathrm{a}, M, \lambda}=e^{-\mathrm{AMF} \cdot\left[a_{0, \lambda}+a_{1, \lambda} M^{1}+a_{2, \lambda} M^{2}\right]}$.

The atmospheric correction coefficients for the AATSR channels are listed in Table 1.

To account for atmospheric absorption below the cloud, the surface albedo in Eq. (2) is adjusted to a so-called virtual surface albedo $\alpha_{\mathrm{v}}$ by multiplying the surface albedo with the atmospheric transmittance below the cloud. The atmospheric transmittance below the cloud is computed in the same manner as the atmospheric transmittance above the cloud. For the computation of the atmospheric transmittance below the cloud, a diffuse radiation field below the cloud is assumed, which means that an air mass factor of 2 is used. Rayleigh scattering is not considered below the cloud. The altitude of the cloud is roughly estimated using the AATSR $11 \mu \mathrm{m}$ brightness temperature and atmospheric temperature and pressure profiles from model data (described in Sect. 3.3). The full forward model looks as follows:

$R_{\mathrm{toc}, \mathrm{v}, \lambda}=R_{\mathrm{c}, \lambda}+\frac{\alpha_{\mathrm{v}, \lambda} \cdot t_{\mathrm{c}, \lambda}\left(\theta_{0}, \tau, r_{\mathrm{eff}}\right) \cdot t_{\mathrm{c}, \lambda}\left(\theta, \tau, r_{\mathrm{eff}}\right)}{1-\alpha_{\mathrm{v}, \lambda} \cdot S_{\lambda}\left(\tau, r_{\mathrm{eff}}\right)}$.

Cloud reflectance, cloud transmittance, spherical albedo and cloud albedo have all been computed for both water and ice clouds. For radiative transfer simulations with water clouds, Mie calculations (Wiscombe, 1980) have been performed beforehand to compute scattering phase functions as well as single-scattering albedo and normalized extinction coefficient, which serve as input to MOMO. In the Mie calculations a modified gamma-Hansen cloud droplet size distribution $n(r)$ is assumed (Hansen and Travis, 1974), where the mode radius equals the effective radius (Hansen and Hovenier, 1974):

$r_{\mathrm{eff}}=\frac{\int_{0}^{\infty} r^{3} n(r) \mathrm{d} r}{\int_{0}^{\infty} r^{2} n(r) \mathrm{d} r}$,

where $r$ is the cloud droplet radius. A value of 0.1 for the effective variance is assumed for this droplet size distribution (Minnis et al., 1998). For ice clouds, single-scattering properties described in Baum et al. (2005) have been used in the radiative transfer simulations. In the LUTs the COT and REF (in $\mu$ ) range in $\log _{10}$ space from -0.6 to 2.2 in 29 steps and 0.4 to 2.0 in 9 steps, respectively.

From the $\tau-r_{\text {eff }}$ pair the liquid water path (LWP) for water clouds and the ice water path (IWP) for ice clouds are determined, assuming a plane-parallel homogeneous cloud, as follows:

$\mathrm{CWP}=\frac{2}{3} \cdot \tau \cdot r_{\mathrm{eff}} \cdot \rho$,

where $\rho$ is the density of liquid or frozen water $\left(\mathrm{g} \mathrm{m}^{-3}\right)$. For optically thin ice clouds the following equation is used to compute ice water path, which is based on observations of mid-latitude thin ice clouds (Heymsfield et al., 2003):

$\mathrm{IWP}=\tau \cdot\left[\frac{g_{0}}{r_{\mathrm{eff}}} \cdot\left[1+\frac{g_{1}}{g_{0}}\right]\right]^{-1}$,

where $g_{0}$ and $g_{1}$ are constants with values 0.01256 and 0.725 , respectively.

The cloud phase discrimination is done using a simple brightness temperature (BT) threshold of $261 \mathrm{~K}$ for the 
AATSR $11 \mu \mathrm{m}$ channel, combined with a cirrus detection using the brightness temperature difference $\mathrm{BT}_{11}-\mathrm{BT}_{12}$ technique (Saunders and Kriebel, 1988) and a maximum reflectance in the visible of 0.25 . At $261 \mathrm{~K}$ the difference in equilibrium water vapor pressure with respect to ice and water is largest, favoring the growth of ice crystals over supercooled water droplets for temperatures below $261 \mathrm{~K}$ (Pruppacher and Klett, 1997). For the cirrus detection a dynamic clear-sky brightness temperature difference threshold, depending on atmospheric moisture and surface temperature, is used. The clear-sky radiative transfer simulations have been performed with MOMO using a set of standard atmospheric profiles as input taken from McClatchey et al. (1972). From visual inspection of retrieved cloudy scenes the method also often appears to detect cloud edges.

\subsection{Cloud top heights}

Two cloud top height products are retrieved within FAME-C. First, the cloud top temperature (CTT) using AATSR brightness temperatures is retrieved. Second, the cloud top pressure (CTP) is retrieved using the ratio of the MERIS oxygenA absorption channel over a nearby window channel. Both cloud top height retrievals are then converted into cloud top heights (in $\mathrm{km}$ ) using the input atmospheric profiles.

\subsubsection{AATSR cloud top temperature}

The cloud top temperature is retrieved using measurements at the $11 \mu \mathrm{m}$ channel and the $12 \mu \mathrm{m}$ channel, at which the extinction coefficient of water is larger. The forward model, assuming a plane-parallel atmosphere, consists of three parts contributing to the top-of-atmosphere radiation in cloudy situations: cloud, surface and atmosphere. The contribution of the cloud $I_{\mathrm{c}, \lambda}$ is given as follows:

$I_{\mathrm{c}, \lambda}=\epsilon_{\mathrm{c}}(\tau, \theta) \cdot B\left(T_{\mathrm{ct}}, \lambda\right) \cdot t_{\mathrm{ct} \rightarrow 1, \lambda}(\theta)$,

where $\epsilon_{\mathrm{c}}$ is the cloud emissivity; $B\left(T_{\mathrm{c}}\right)$ is the Planck function at the temperature of the cloud top $T_{\mathrm{ct}}$, assuming the cloud to be in thermal equilibrium with the surrounding air; and $t_{\mathrm{ct} \rightarrow 1}$ is the atmospheric transmittance from the cloud top to the top of atmosphere. The cloud emissivity is computed as follows:

$\epsilon_{\mathrm{c}}=1-\exp \left[\frac{-\tau_{\mathrm{ir}}}{\cos \theta}\right]$,

where $\tau_{\text {ir }}$ is the cloud optical thickness in the thermal infrared. Here, no multiple scattering is assumed and the thermal infrared cloud optical thickness is computed from the visible cloud optical thickness $\tau_{\text {vis }}$, which is taken from the cloud optical and microphysical property retrieval. The simple relationship $\tau_{\text {ir }}=0.5 \cdot \tau_{\text {vis }}$ is used, which is about true for large water and ice particles (Minnis et al., 1993).

The contribution of the surface $I_{\mathrm{s}, \lambda}$ is given as follows:

$I_{\mathrm{s}, \lambda}=\epsilon_{\mathrm{s}, \lambda} \cdot B\left(T_{\mathrm{s}}, \lambda\right) \cdot t_{\mathrm{a}, \lambda}(\theta) \cdot t_{\mathrm{c}}(\theta)$, where $\epsilon_{\mathrm{S}}$ is the surface emissivity, $B\left(T_{\mathrm{S}}\right)$ is the Planck function at the surface temperature $T_{\mathrm{S}}, t_{\mathrm{a}}$ is the transmittance of the atmosphere, and $t_{\mathrm{c}}$ is the transmittance of the cloud. The cloud transmittance is computed from the cloud emissivity with $t_{\mathrm{c}}=1-\epsilon_{\mathrm{c}}$. The contribution of the atmosphere at the top of atmosphere $I_{\mathrm{a}, \lambda}$ is given as follows:

$$
\begin{aligned}
& I_{\mathrm{a}, \lambda}= \\
& \quad \int_{t_{\mathrm{s}, \lambda}}^{1} B\left(T_{\mathrm{a}}, \lambda\right) \mathrm{d} t_{\lambda}+\left[1-\epsilon_{\mathrm{s}, \lambda}\right] \cdot t_{\mathrm{s}, \lambda}(\theta)^{2} \cdot \int_{t_{\mathrm{s}, \lambda}}^{1} \frac{B\left(T_{\mathrm{a}}, \lambda\right)}{t_{\lambda}(\theta)^{2}} \mathrm{~d} t_{\lambda},
\end{aligned}
$$

where $t_{\mathrm{S}}$ is the total transmittance from surface to the top of the atmosphere, and $B\left(T_{\mathrm{a}}\right)$ is the Planck function at the atmospheric temperature $T_{\mathrm{a}}$ of the level with transmittance $t$. The second term in the equation is of second order and arises from downward radiance reflected upward at the surface. For cloudy layers, the atmospheric transmittance $t_{\mathrm{a}, j}$ of layer $j$ is multiplied by the cloud transmittance $t_{\mathrm{c}, j}$ to get the total transmittance $t$ at layer $j$. The vertical extension of the cloud and the vertical distribution of cloud layer transmittance/emissivity values are based on vertical cloud profiles explained in Sect. 3.2.2. For atmospheric levels below the cloud the atmospheric transmittances are multiplied by the total cloud transmittance $t_{\mathrm{c}}$. For very thick clouds with cloud emissivities equal to 1 , the surface and atmospheric layers below the cloud do not contribute to the top-of-atmosphere radiance.

The fast radiative transfer model RTTOV version 9.3 (Saunders et al., 2010; METOffice, 2014) is used to simulate the clear-sky transmission for both AATSR IR channels at a given number of atmospheric levels. Given as input into RTTOV are atmospheric profiles of temperature, water vapor and ozone concentrations, as well as the temperature, water vapor concentration and pressure near the surface. Both the atmospheric profiles and surface properties are obtained from ERA-Interim reanalysis and forecasts (to be described in Sect. 3.3). At the time of development the optical parameter file for ATSR on ERS (version 7) was used. This will lead to a small error in the simulated AATSR brightness temperatures due to slightly different spectral response functions for the IR channels of the two instrument.

\subsubsection{MERIS cloud top pressure}

The cloud top pressure (CTP) is retrieved using the radiance ratio of the MERIS oxygen-A absorption channel 11 at around $760 \mathrm{~nm}\left(\mathrm{~L}_{11}\right)$ and a nearby window channel 10 at around $753 \mathrm{~nm}\left(\mathrm{~L}_{10}\right)$, representing an apparent transmittance:

$t_{\mathrm{O}_{2}}=\frac{\mathrm{L}_{11}}{\mathrm{~L}_{10}}$.

Since oxygen is a well-mixed gas in the atmosphere, the ratio can be used to estimate the average photon path length 
through the atmosphere. In cloudy situations this average photon path length mainly depends on cloud top pressure.

MOMO radiative transfer simulations have been performed to create a LUT in which the ratio depends on cloud top pressure as well as cloud optical thickness, viewing geometry, surface pressure and the MERIS channel 11 center wavelength. A US standard atmosphere (McClatchey et al., 1972) is assumed in the simulations. The $k$-distribution method (Bennartz and Fischer, 2000; Doppler et al., 2014) is used to compute the absorption coefficients of the atmospheric gases. Information on the position and width of absorption lines is taken from the HITRAN database (Rothman et al., 2009). The CTP ranges from 100 to $1000 \mathrm{hPa}$ in the LUT. For cloud layers below $440 \mathrm{hPa}$, ice crystals are assumed with a fixed effective radius of $40 \mu \mathrm{m}$; otherwise water droplets are assumed with a fixed effective radius of $10 \mu \mathrm{m}$. A previous sensitivity study (Preusker and Lindstrot, 2009) has shown that the cloud microphysical properties and the temperature profile account for errors of less than 10 and 20 $\mathrm{hPa}$, respectively, in the MERIS-CTP retrieval and are much smaller than other error sources such as the presence of multilayer clouds and unknown subpixel cloud fraction. For CTP retrievals above high land surfaces, the surface pressure has to be taken into account to prevent underestimation of CTP. For retrievals above oceans a surface pressure of $1013 \mathrm{hPa}$ is assumed. To account for the spectral smile effect in the MERIS measurements, radiative transfer simulations are performed for varying center wavelengths in the oxygen-A absorption channel.

Due to in-cloud scattering, the average photon path length is increased. This increase depends on the vertical extinction profile of the cloud. To derive "realistic" cloud vertical extinction profiles for nine cloud types based on the ISCCP cloud classification (ISCCP), 1 year (2010) of layer optical thicknesses as provided by the CloudSat database is used as described in Henken et al. (2013). The geometrical thickness of each cloud type, i.e., the number of adjacent cloud layers with a thickness of $20 \mathrm{hPa}$, is taken constant and based on an empirical analysis of a number of CloudSat scenes. The resulting averaged and normalized vertical extinction profiles are shown in Fig. 1. For most cloud types it can be seen that lower cloud layers tend to have higher extinction values than upper cloud layers. In the radiative transfer simulations of the MERIS channels 10 and 11 radiances, the cloud is divided into a number of cloud layers, each with a thickness of $20 \mathrm{hPa}$. The appropriate extinction profile, and thus the extinction of each cloud layer, is selected according to the ISCCP cloud classification. This means that the layer cloud optical thickness is different for each cloud layer, while it would be taken constant for all cloud layers when assuming a vertically homogeneous cloud. The total cloud optical thickness is taken from the cloud optical and microphysical property retrieval.

\subsection{Auxiliary data}

A set of auxiliary data is needed within the FAME-C algorithm. For the atmospheric correction in the cloud optical and microphysical property retrieval, atmospheric profiles from ERA-Interim reanalyses $(00+00$ and $12+00$ UTC) and forecasts $(00: 00+6 \mathrm{~h}$ and 12:00 UTC +06$)$ are used. They are linearly interpolated in time, but kept on the ERAInterim spatial resolution of $1.125^{\circ}$. The interpolated atmospheric profiles and surface properties also serve as input in the RTTOV clear-sky simulations. Furthermore, the IR land surface emissivities are taken from the UW-Madison Baseline Fit Emissivity Database (Seemann et al., 2008). The cloud optical and microphysical property retrieval uses the MODIS 16-day composite white-sky surface albedo product (MCD43C3; NASA Land Processes Distributed Active Archive Center (LP DAAC)) on a $0.05^{\circ}$ spatial grid as input, while the MERIS-CTP retrieval uses the 2005 monthly mean MERIS-derived land surface albedo product (Muller et al., 2007). To account for pixels that might contain snow-covered surfaces, the MODIS monthly mean snow cover product (MYD10CM; Hall and Riggs., 2006) on a spatial $0.05^{\circ}$ grid is used. Sea ice cover is taken from ERA-Interim. For water surfaces and surfaces containing snow or ice fractions of more than $50 \%$, fixed surface albedo and surface emissivity values are taken from narrowband mean surface albedo (Chen et al., 2006) and surface emissivity (Chen et al., 2003) for water and snow/ice surfaces derived from MODIS-Terra data. The surface pressure that serves as input in the MERISCTP retrieval is estimated on a pixel basis from the MERIS surface height provided as meta-data in the AATSR-MERIS synergy product. The synergy product also provides for a pixel-based land-sea mask.

\section{Retrieval scheme}

The FAME-C cloud property retrieval is conducted orbitwise on a pixel basis and in a sequential form. First, preprocessing is performed by creating the synergy files with cloud mask as well as extracting auxiliary data. Then, for pixels identified as cloudy during the cloud screening, the cloud optical and microphysical properties retrieval is performed (DCOMP). Last, two independent cloud top height retrievals are performed (DCHP; Daytime Cloud top Height Properties). First, cloud top temperature is retrieved using AATSR IR measurements (DCHP-A). Second, cloud top pressure is retrieved using MERIS measurements in the oxygen-A absorption channel and a nearby window channel (DCHP-M). Note that the cloud optical thickness from the cloud optical and microphysical property retrieval serves as input for both DCHP retrievals. Figure 2 gives a schematic overview of the FAME-C algorithm. 

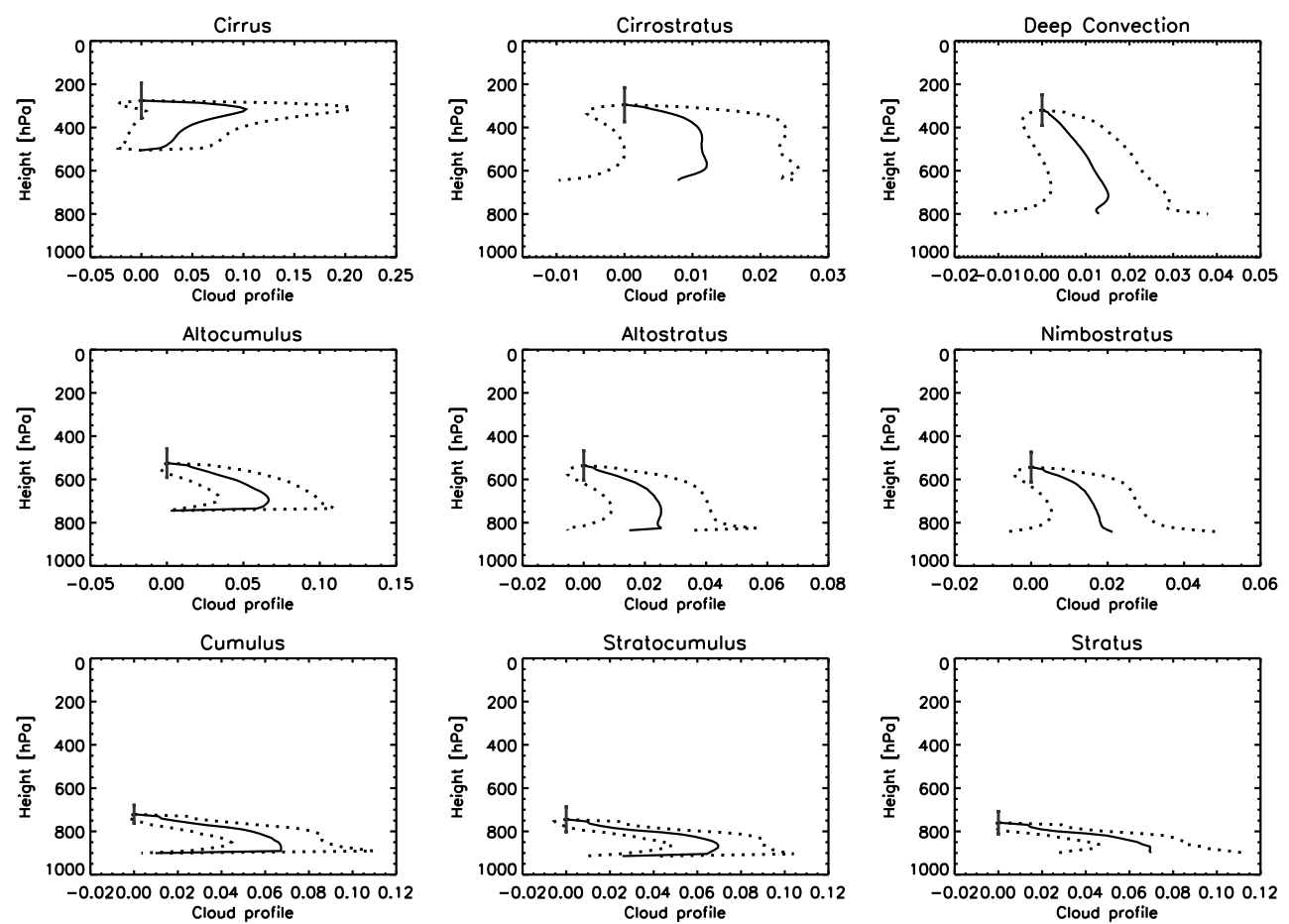

Figure 1. Normalized mean cloud vertical extinction profiles (solid line) for nine cloud types based on the ISCCP cloud classification. The standard deviation of extinction is shown by the dotted line, and the standard deviation of the cloud top pressure is shown by the error bar.

\subsection{Inversion technique}

The retrieval of the cloud parameters is based on the optimal estimation method. This inversion technique allows for the combined use of an a priori estimate of the most likely solution, $\boldsymbol{x}_{\mathrm{a}}$, and the measurements given in the measurement vector $\boldsymbol{y}$ to maximize the probability of the retrieved cloud parameters given in the state vector $\boldsymbol{x}$. The cloud parameters, their a priori values with uncertainties, and measurements with uncertainties are listed in Table 2. Both $\boldsymbol{x}_{\mathrm{a}}$ and $\boldsymbol{y}$ are weighted by their uncertainty estimates given in the error covariance matrices $\mathbf{S}_{\mathrm{a}}$ and $\mathbf{S}_{y}$, respectively. In short, the inversion technique aims to minimize the retrieval cost function $J$ given as

$$
\begin{aligned}
J(x) & =[\boldsymbol{y}-F(\boldsymbol{x}, \boldsymbol{b})]^{T} \mathbf{S}_{y}^{-1}[\boldsymbol{y}-F(\boldsymbol{x}, \boldsymbol{b})] \\
& +\left[\boldsymbol{x}-\boldsymbol{x}_{\mathrm{a}}\right]^{T} \mathbf{S}_{\mathrm{a}}^{-1}\left[\boldsymbol{x}-\boldsymbol{x}_{\mathrm{a}}\right],
\end{aligned}
$$

where $F(\boldsymbol{x}, \boldsymbol{b})$ is the output of the forward model for state $\boldsymbol{x}$ and background state $\boldsymbol{b}$. The forward model parameters and their uncertainties are listed in Table 3. The background state vector, or forward model parameter vector, includes parameters that are not retrieved but do affect the retrieval. Due to nonlinearity in the forward model the minimization is performed within an iterative process. Here, the Gauss-Newton method is used. A first guess, also listed in Table 3, is used to start the iteration. The iteration is terminated when the difference between the error-weighted length of two consecutive state vectors is 1 order of magnitude smaller than the length of the state vector, or the maximum number of allowed iterations has been reached. The error covariance matrix of the retrieved state $\mathbf{S}_{x}$ can be computed as follows:

$\mathbf{S}_{x}=\left[\mathbf{K}_{T} \mathbf{S}_{y}^{-1} \mathbf{K}+\mathbf{S}_{\mathrm{a}}^{-1}\right]^{-1}$,

where $\mathbf{K}$ is the Jacobian matrix describing the sensitivity of $F$ to changes in state parameters. This way, the pixel-based retrievals are accompanied by pixel-based uncertainties.

It has to be noted that the optimal estimation method is built on the assumption that the state parameters and their errors, as well as the observation errors, show a Gaussian distribution, and the iteration method assumes that $F$ changes linearly with small changes in the state parameters. To meet these assumptions, the $\tau-r_{\text {eff }}$ pair is retrieved in a logarithmbased space. An in-depth mathematical description of optimal estimation can be found in Rodgers (2000).

Figure 3 shows an example of the cloud mask and retrieved cloud parameters for a cloudy scene above Germany.

\subsection{Uncertainty estimates}

The reliability of the error covariance matrix of the retrieved state depends on the reliability of the characterization of $\mathbf{S}_{y}$ and $\mathbf{S}_{\mathrm{a}}$, i.e., on the estimated uncertainties in the measurements and the a priori state. Also, forward model parameter uncertainties, which are uncertainties caused by nonretrieved 


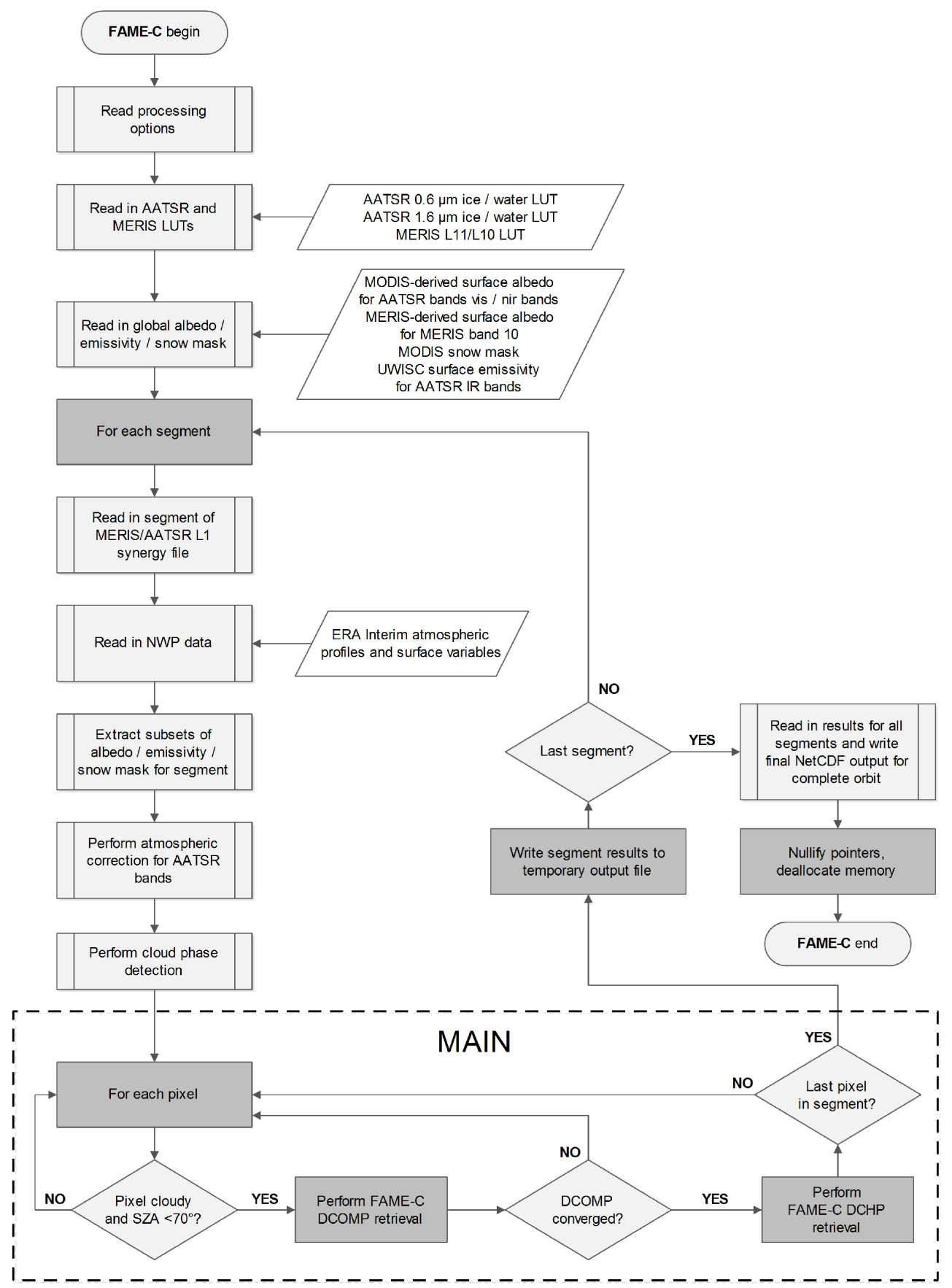

Figure 2. FAME-C algorithm flowchart with two main retrieval steps DCOMP (Daytime Cloud Optical and Microphysical Properties) and DCHP (Daytime Cloud top Height Properties) and input and output data.

parameters in the forward model, can be added to the measurement uncertainties to form a combined measurement error covariance matrix $\mathbf{S}_{\epsilon}$ as follows:

$\mathbf{S}_{\epsilon}=\mathbf{S}_{y}+\mathbf{K}_{B} \mathbf{S}_{B} \mathbf{K}_{B}^{T}$,

where $\mathbf{S}_{B}$ is the forward model error covariance matrix and $\mathbf{K}_{B}$ is the Jacobian matrix, which describes the sensitivity of $F$ to changes in the forward model parameters.
At the moment, all error covariance matrices only have nonzero values for the diagonal elements, meaning that correlations between uncertainties are neglected. Furthermore, we do not make use of an independent source that can provide for well-characterized a priori knowledge of the cloud parameters and their uncertainties. Therefore, the estimated uncertainties are set to high values, shown in Table 2. This will reduce the constraint of the a priori estimate $\boldsymbol{x}_{\mathrm{a}}$ on possi- 
Table 2. Listed are the variables in the state vector $\boldsymbol{x}$, the measurements in the measurement vector $\boldsymbol{y}$ ( $R$ : reflectance; BT: brightness temperature; $L$ : radiance) and their uncertainties $\boldsymbol{y}_{\text {unc }}$, and the a priori values in the a priori state vector $\boldsymbol{x}_{\mathrm{a}}$ and their uncertainties $\boldsymbol{x}_{\mathrm{a} \text { unc }}$, used in the Daytime Cloud Optical and Microphysical Cloud Properties retrieval (DCOMP) and both Daytime Cloud Top Height properties retrievals for AATSR measurements (DCHP-A), and MERIS measurements (DCHP-M). Here, wat and ice are the water and both Daytime Cloud Top Height Properties retrieval for ice cloud phases, respectively. Note that $\boldsymbol{x}_{\mathrm{a}}$ and $\boldsymbol{x}_{\mathrm{a} \_ \text {unc }}$ are in $\log _{10}$ space in DCOMP.

\begin{tabular}{llll}
\hline Algorithm & $\boldsymbol{x}$, (symbol) [unit] & $\boldsymbol{y}: \boldsymbol{y}_{\mathrm{unc}}$ & $\boldsymbol{x}_{\mathrm{a}}: \boldsymbol{x}_{\mathrm{a} \_ \text {unc }}$ \\
\hline DCOMP & COT $(\tau)$ & $R 0.66 \mu \mathrm{m}: 4 \%$ & wat $=1.0: 2.0$, ice $=1.0: 2.0$ \\
& REF $\left(r_{\mathrm{eff}}\right)[\mu \mathrm{m}]$ & $R 1.6 \mu \mathrm{m}: 4 \%$ & wat $=1.2: 2.0$, ice $=1.6: 2.0$ \\
\hline DCHP-A & CTT $[\mathrm{K}]$ & BT $11 \mu \mathrm{m}: 0.1 \mathrm{~K}$ & wat $=280 \mathrm{~K}: 40 \mathrm{~K}$, ice $=250 \mathrm{~K}: 40 \mathrm{~K}$ \\
& & BT $12 \mu \mathrm{m}: 0.1 \mathrm{~K}$ & \\
\hline DCHP-M & CTP $[\mathrm{hPa}]$ & L $761 \mathrm{~nm} / \mathrm{L} 753 \mathrm{~nm}: 0.004 \%$ & wat $=800 \mathrm{hPa}: 300 \mathrm{hPa}$, ice $=300 \mathrm{hPa}: 300 \mathrm{hPa}$ \\
\hline
\end{tabular}

Table 3. Listed are the forward model parameters $\boldsymbol{b}$ and their uncertainties $\boldsymbol{b}_{\text {unc }}$ as well as the first guess $\boldsymbol{x}_{\text {guess }}$ used in the Daytime Cloud Optical and Microphysical Cloud Properties (DCOMP) retrieval and both the Daytime Cloud top Height Properties for AATSR (DCHP-A) and MERIS measurements (DCHP-M). The cloud optical thickness (COT, $\tau$ ) uncertainty, $\tau_{\text {unc }}$, is taken from the DCOMP results. Misc stands for miscellaneous and is an estimated forward model parameter uncertainty arising from differences in spectral response function of ATSR-2 (assumed in clear-sky RTTOV simulations) and AATSR, as well as tabular integration. In the cloud top pressure (CTP) retrieval, different first guesses are used for low $(>680 \mathrm{hPa})$, middle $(>400$ and $<680 \mathrm{hPa})$ and high $(<400 \mathrm{hPa})$ clouds. To estimate the cloud height level, the previously retrieved cloud top temperature is converted to cloud top pressure using the ERA-Interim temperature profile. Here, $\alpha$ is surface albedo; $\epsilon_{\mathrm{c}}$ is cloud emissivity; wat and ice are the water and ice cloud phases, respectively; $R_{0.66}$ and $R_{1.6}$ are the reflectances in the AATSR 0.66 and $1.6 \mu \mathrm{m}$ channels, respectively; and $\mathrm{BT}_{11}$ is the brightness temperature in the AATSR $11 \mu \mathrm{m}$ channel. Note that $\boldsymbol{x}_{\text {guess }}$ is in $\log _{10}$ space in DCOMP. ${ }^{*}$ Only performed for pixels with $\tau<8$.

\begin{tabular}{|c|c|c|c|}
\hline Algorithm & $x$ & $\boldsymbol{b}: \boldsymbol{b}_{\text {unc }}$ & $\boldsymbol{x}_{\text {guess }}$ \\
\hline DCOMP & $\begin{array}{l}\text { COT } \\
\text { REF }\end{array}$ & $\alpha: 0.02 \&$ CTP: $20 \mathrm{hPa}$ & $\begin{array}{l}\text { wat }=1+R_{0.66}, \text { ice }=1+R_{0.66} \\
\text { wat }=1.2, \text { ice }=1.6-R_{1.6}\end{array}$ \\
\hline DCHP-A & CTT & $\begin{array}{l}\epsilon_{\mathrm{c}}^{*}: \tau_{\text {unc }} / 2 \cos (\theta) \cdot \exp (-\tau / 2 \cos (\theta)) \\
\& \text { Misc: } 0.5 \mathrm{~K}\end{array}$ & $\mathrm{BT}_{11}$ \\
\hline DCHP-M & CTP & $\alpha^{*}: 0.02 \& \tau^{*}: \tau_{\text {unc }}$ & $\begin{array}{l}\text { low }=850 \mathrm{hPa} \text {, } \\
\text { middle }=540 \mathrm{hPa} \text {, } \\
\text { high }=300 \mathrm{hPa}\end{array}$ \\
\hline
\end{tabular}

ble solutions $\boldsymbol{x}$. Estimated uncertainties in the measurements (based on ESA (2014b) for AATSR) as well as for a set of forward model parameters are listed in Tables 2 and 3, respectively. For certain pixels that have reached convergence, we take into account the uncertainties due to the rather simple cloud phase discrimination. This is realized by adding the difference in forward model values between the water cloud and ice cloud, keeping everything else constant, to the measurement error covariance matrix. This is done for pixels with $11 \mu \mathrm{m}$ brightness temperatures between 245 and $273 \mathrm{~K}$ and where the reflectance pair 0.66-1.6 $\mu \mathrm{m}$ lies within both the water and ice cloud LUT. Figure 4 shows the atmospheric corrected 0.66 and $1.6 \mu \mathrm{m}$ reflectances for cloudy pixels from the scene as shown in Fig. 3 together with the AATSR LUT reflectances for a mean viewing geometry and surface albedo, as a function of cloud optical thickness and effective radius and for both water and ice clouds. Shown in green are the cloudy pixels with an uncertain retrieved cloud phase located in the overlapping area of the water and ice
LUT. According to our forward models in this area we can have both large water droplets and small ice crystals or a mix of both.

The retrieved uncertainties for all successfully retrieved cloudy pixels - which are defined as cloudy pixels that converged within the allowed maximum number of iterations and with cost $<20$, for all orbit segments covering a region in Germany as presented in Fig. 5 (GER), and for each retrieved cloud phase - are shown in Fig. 6. For COT, REF and CWP, the mean relative uncertainty is lowest for about $10,10 \mu \mathrm{m}$ and $80 \mathrm{~g} \mathrm{~m}^{-2}$, respectively, and increases for both decreasing and increasing values of the accompanying cloud properties. For both CTT and CTP the relative uncertainty decreases for decreasing cloud top height. The shapes can be largely explained as follows. For thin clouds, the uncertainties in surface albedo and cloud emissivity make a large contribution to the total uncertainty. For very thick clouds the reflectance in the visible is less sensitive to cloud optical thickness, leading to increased uncertainty in COT. The uncertainties in cloud 

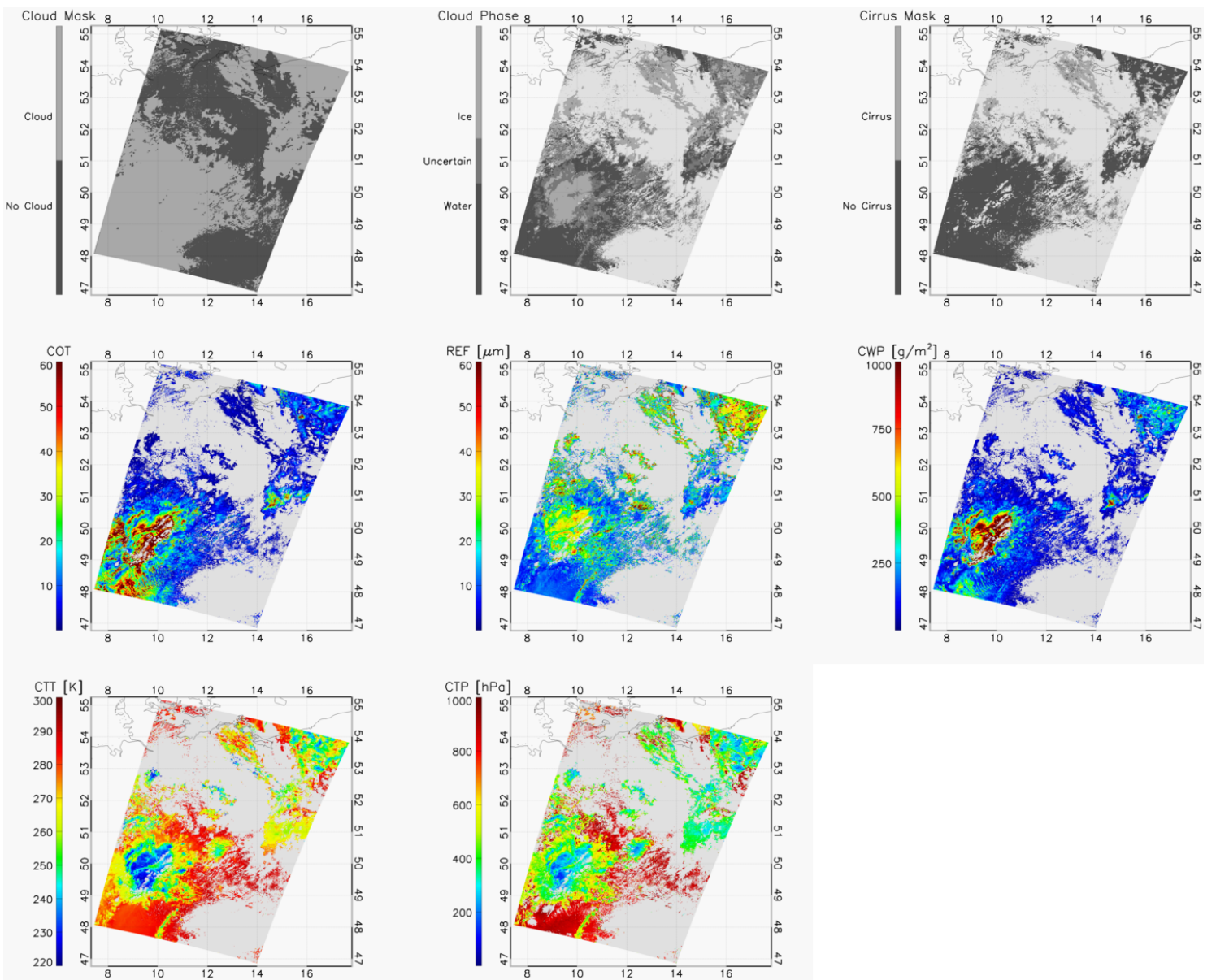

Figure 3. Example of the FAME-C cloud mask; cloud phase mask; cirrus mask; and retrieved cloud optical, microphysical and macrophysical properties for a synergy AATSR-MERIS orbit segment above Germany on 21 July 2007.

emissivity and COT are propagated to uncertainties in CTT and CTP, respectively. In general, the relative uncertainty is highest for pixels with uncertain cloud phase and lowest for water cloud pixels.

Uncertainties in ERA-Interim atmospheric profiles are neglected. Also, uncertainties in the radiative transfer simulations and chosen cloud microphysical models, as well as those due to interpolations in the LUTs, are not considered at present.

Last, the forward model assumes fully cloudy pixels with plane-parallel clouds consisting of either water droplets or ice crystals. The impact of subpixel clouds, threedimensional effects (e.g., cloud shadows), multilayer cloud situations and mixed-phase clouds needs to be studied in the future for an improved uncertainty estimate budget.

\section{Verification}

To verify the performance of the FAME-C cloud properties, two comparisons were performed for selected areas and for the years 2007-2009.

\subsection{Comparison to MODIS-Terra level-2 cloud optical and microphysical properties}

The comparison of the FAME-C level-2 cloud optical and microphysical properties to the MODIS-Terra level-2 cloud optical and microphysical properties (MOD06 collection-5 cloud products) is performed for four selected regions as shown in Fig. 5. For each region, all available orbit segments of both Envisat and Terra are collected. Overpasses of the satellites Terra and Envisat do not necessarily occur on the same days. Therefore, no pixel-based comparison is possible. From all selected cloudy pixels within the region and within 1 month, monthly means and standard deviations are produced for each of the cloud optical and microphysical properties.

For both, only cloudy pixels with satellite viewing angles of $<21.6^{\circ}$, which is the maximum AATSR satellite viewing angle, and solar zenith angles of $<70^{\circ}$, are considered. For MODIS-Terra level-2, the effective radius is limited to $30 \mu \mathrm{m}$ for water clouds. In this comparison this is also done for FAME-C effective radius for water clouds. Furthermore, 


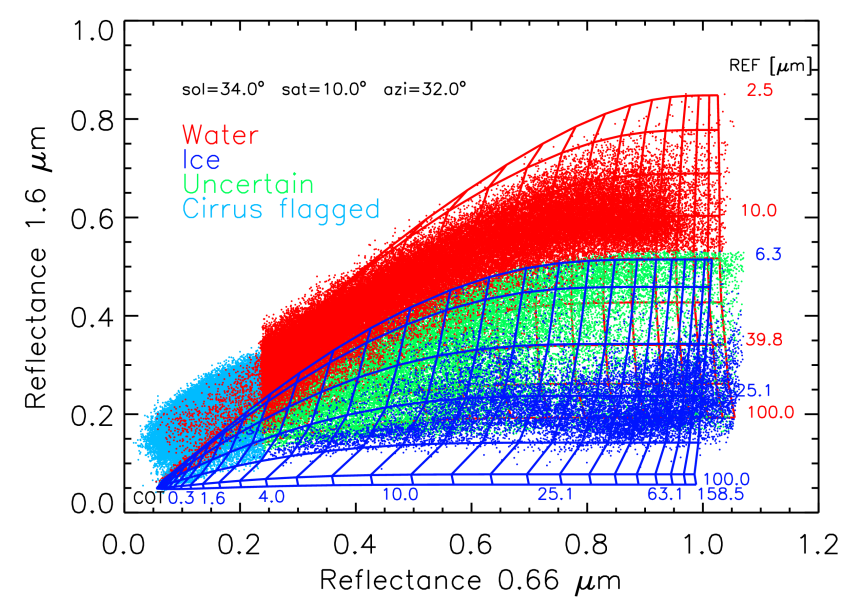

Figure 4. AATSR atmospheric corrected reflectance in the visible and near infrared (dots) for water, ice, uncertain and cirrus pixels from the scene shown in Fig. 3. The two grids represent the forwardmodeled AATSR reflectances for water (red) and ice (blue) clouds, assuming mean viewing geometry and surface albedo values for the scene.

for the MODIS cloud optical and microphysical properties cloudy pixels with a general assessment set to Useful according to the quality flag (quality assurance at $1 \times 1$ resolution) are selected. For FAME-C, successfully retrieved cloudy pixels, as defined in Sect. 4.2, are selected.

Figure 7 shows the frequency distribution of COT, REF and CWP for all retrieved cloudy pixels in the time period 2007-2009 for both FAME-C and MODIS-Terra for two selected regions, GER and NAM, as presented in Fig. 5. Also, a distinction in cloud phase is made. Generally, the overall distributions agree well with similar shapes and peaks located around similar values. This is expected, especially for NAM, since one cloud regime, marine stratocumulus clouds, dominates this region. Differences become larger when only considering one specific cloud phase. For NAM both FAME-C and MODIS-Terra agree that almost all pixels consist of the water cloud phase. For both regions, FAME-C has a larger number of pixels with uncertain cloud phase. A major difference is the sharp peak at low COT values for FAME-C, mainly consisting of ice phase. We assume this to be pixels misidentified as cirrus clouds through the cirrus detection method, and the peak vanishes when these pixels are not considered. Consequently, the peak CWP is shifted towards lower values for FAME-C. The FAME-C REF values agree very well with the MODIS-Terra REF values for NAM. In GER, the second peak in the MODIS-Terra REF arising from the ice cloud phase is not visible in FAME-C REF.

Table 4 lists, for each region and cloud property, the bias and root-mean-square deviation (RMSD) computed from the monthly means in the 3-year time period. They have been computed for all successfully retrieved cloudy pixels (All), and separately for cloudy pixels identified as water cloud

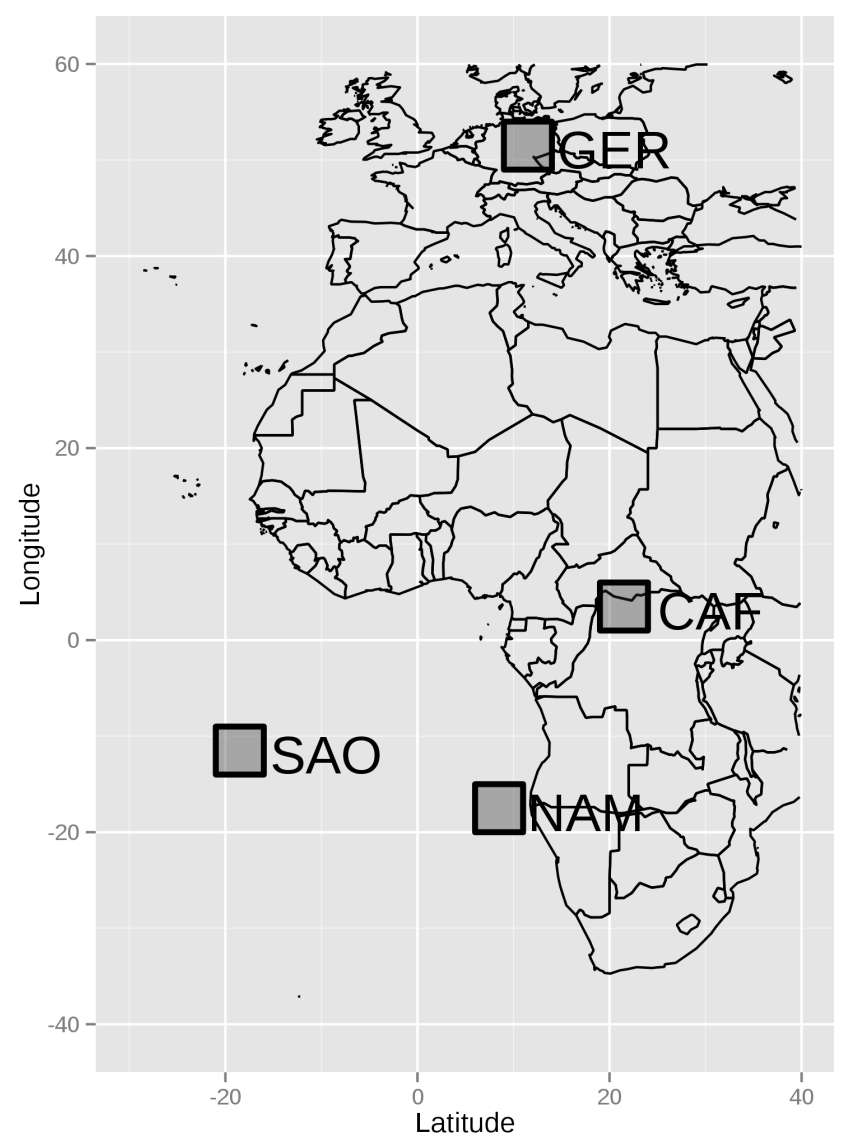

Figure 5. Map showing four regions where level-2-based comparisons between FAME-C and MODIS-Terra cloud properties are conducted for the years 2007-2009. SAO: southern Atlantic Ocean; NAM: coast of Namibia; CAF: central Africa; GER: Germany.

(Wat), ice cloud (Ice) and with uncertain cloud phase (Unc). The cloud fraction here is defined as the cloud fraction which only considers successfully retrieved cloudy pixels, so those pixels contributing to the statistics of the cloud optical and microphysical properties. The cloud phase fractions are considered relative to this overall retrieval cloud fraction. It should be emphasized that the cloud fractions and the fraction of clouds with a specific phase, in particular uncertain cloud phase, can be quite different for FAME-C and MODISTerra, and consequently this will affect the statistics of the other cloud properties.

For three regions, FAME-C shows an overall cloud fraction that is higher than the MODIS-Terra overall cloud fraction (positive bias), especially for the regions over the ocean (NAM and SAO). This may be partly explained by the clearsky restoral in the MODIS-Terra cloud property retrieval and likely a more strict quality assessment than in FAME-C. The relative water cloud fraction is usually lower for FAME-C, while the uncertain cloud fraction is higher for FAME-C. Generally, the overall tendency is that FAME-C shows lower COTs and higher REFs. Especially noticeable is the COT 
Table 4. Results of the comparison with monthly mean MODIS-Terra cloud optical and microphysical properties for four regions as presented in Fig. 5. Performed for all successfully retrieved cloudy pixels (All), and separately for water cloud pixels (Wat), ice cloud pixels (Ice), and cloudy pixels with uncertain phase (Unc), for cloud properties cloud fraction (CF), cloud optical thickness (COT), effective radius (REF) and cloud water path (CWP). REF16 is the MODIS-Terra effective radius retrieved using the $1.6 \mu$ m channel. RMSD is root-mean-square deviation.

\begin{tabular}{|c|c|c|c|c|c|c|c|c|c|}
\hline & & \multicolumn{4}{|c|}{ Bias } & \multicolumn{4}{|c|}{ RMSD } \\
\hline & & All & Wat & Ice & Unc & All & Wat & Ice & Unc \\
\hline \multirow[t]{5}{*}{ CAF } & $\mathrm{CF}[\%]$ & -1.87 & -10.13 & -1.95 & 21.83 & 12.45 & 16.24 & 6.73 & 22.87 \\
\hline & COT [1] & -1.54 & 0.58 & -3.73 & -2.70 & 4.84 & 2.08 & 7.40 & 7.52 \\
\hline & $\mathrm{REF}[\mu \mathrm{m}]$ & 0.07 & -1.49 & 0.92 & 0.28 & 3.48 & 1.95 & 4.10 & 2.45 \\
\hline & REF16 [ $\mu \mathrm{m}]$ & -1.06 & -3.11 & 0.42 & 0.21 & 3.56 & 3.33 & 4.13 & 2.03 \\
\hline & $\mathrm{CWP}\left[\mathrm{g} \mathrm{m}^{-2}\right]$ & 21.62 & 4.61 & 29.05 & 2.48 & 83.70 & 19.11 & 111.78 & 75.29 \\
\hline \multirow[t]{5}{*}{ GER } & $\mathrm{CF}[\%]$ & 4.70 & -11.97 & -2.39 & 29.81 & 15.59 & 17.26 & 9.66 & 33.82 \\
\hline & COT [1] & -4.57 & -3.02 & -9.70 & -3.03 & 6.20 & 5.80 & 11.91 & 11.18 \\
\hline & $\operatorname{REF}[\mu \mathrm{m}]$ & 2.26 & 0.09 & 4.50 & 0.43 & 3.14 & 1.38 & 5.61 & 3.61 \\
\hline & $\operatorname{REF} 16[\mu \mathrm{m}]$ & 1.64 & -1.01 & 4.18 & 1.10 & 2.78 & 1.90 & 5.83 & 3.04 \\
\hline & $\mathrm{CWP}\left[\mathrm{g} \mathrm{m}^{-2}\right]$ & 0.45 & -8.39 & -40.89 & 11.31 & 40.39 & 35.27 & 107.55 & 86.28 \\
\hline \multirow[t]{5}{*}{ NAM } & $\mathrm{CF}[\%]$ & 7.57 & -2.41 & 0.08 & 0.28 & 12.98 & 6.08 & 0.48 & 2.22 \\
\hline & COT [1] & -0.60 & -0.28 & -4.94 & 7.95 & 1.38 & 1.27 & 7.06 & 10.52 \\
\hline & $\mathrm{REF}[\mu \mathrm{m}]$ & -0.31 & -0.47 & 1.59 & 3.68 & 1.33 & 1.34 & 5.48 & 5.29 \\
\hline & REF16 [ $\mu \mathrm{m}]$ & 0.65 & 0.41 & 3.60 & 4.71 & 1.35 & 1.18 & 6.45 & 6.21 \\
\hline & $\mathrm{CWP}\left[\mathrm{g} \mathrm{m}^{-2}\right]$ & -1.95 & -0.18 & -27.91 & 115.42 & 13.62 & 14.46 & 47.44 & 141.66 \\
\hline \multirow[t]{5}{*}{ SAO } & $\mathrm{CF}[\%]$ & 14.23 & -1.77 & 0.26 & 1.25 & 16.17 & 8.30 & 1.17 & 2.51 \\
\hline & COT [1] & -1.10 & -0.56 & -3.57 & 1.96 & 1.75 & 1.43 & 4.38 & 5.31 \\
\hline & $\operatorname{REF}[\mu \mathrm{m}]$ & 1.11 & 1.11 & -1.44 & 4.38 & 2.41 & 2.18 & 7.04 & 6.58 \\
\hline & REF16 [ $\mu \mathrm{m}]$ & 2.00 & 1.80 & 2.05 & 5.38 & 2.70 & 2.39 & 6.92 & 7.18 \\
\hline & $\mathrm{CWP}\left[\mathrm{g} \mathrm{m}^{-2}\right]$ & -0.28 & 5.20 & -28.78 & 66.98 & 17.25 & 17.16 & 44.56 & 88.68 \\
\hline
\end{tabular}

negative bias for GER. This can be attributed to a large number of optically thin ice clouds retrieved with FAME-C, but not with MODIS-Terra. First inspections have revealed that this is due to misidentified cirrus clouds, which, through visual inspection, appear to be mainly cloud edges. Neglecting those pixels reduces the overall COT, REF and REF16 biases to $-1.92,1.01$ and $0.45 \mu \mathrm{m}$, respectively, but increases the CWP bias to $25.20 \mathrm{~g} \mathrm{~m}^{-2}$.

The bias between the REF where both FAME-C and MODIS-Terra-retrieved REF using the $1.6 \mu \mathrm{m}$ channel (REF16) is not necessarily smaller than the bias when MODIS-Terra uses the $2.1 \mu \mathrm{m}$ channel (REF). The NAM region is dominated by marine stratocumulus clouds, which are relatively horizontally homogeneous and sub-adiabatic (e.g., Pawlowska and Brenguier, 2000). An adiabatic cloud shows an increasing REF with height. The penetration depth at $1.6 \mu \mathrm{m}$ is larger than at $2.1 \mu \mathrm{m}$ and would result in a lower retrieved effective radius assuming an adiabatic cloud. Therefore, in that case a negative bias would be expected when comparing the FAME-C REF retrieved using $1.6 \mu \mathrm{m}$ and MODIS-Terra REF using $2.1 \mu \mathrm{m}$. When comparing both REF retrievals at $1.6 \mu \mathrm{m}$, a slight positive bias is found. Retrievals of REF using different near-infrared channels can, however, also be affected differently by, for example, 3-D radiative effects (e.g., Zhang et al., 2012), which makes interpretation of small differences difficult. The CWP bias is largest for the CAF region. However, this is also the region where deep convection takes place, which can result in very high CWP values. Mostly, biases are largest for pixels with uncertain cloud phase followed by the ice cloud phase. This is also true for the RMSD.

It should be noted that the Terra satellite flies in a Sunsynchronous near-polar orbit with a mean local solar time of 10:30. at descending node, which is half an hour later than the Envisat satellite. Slightly shifted observation times as well as different viewing geometry can also contribute to differences in mean cloud properties.

\subsection{Comparison to cloud top heights derived from ground-based radar observations}

The comparison of FAME-C cloud top height products to cloud top heights derived from ground-based observations is performed at the Atmospheric Radiation Measurement (ARM) program's sites in the Southern Great Plains (SGP), tropical western Pacific (TWP) and North Slope Alaska (NSA). The active remote sensing of clouds (ARSCL) product provides cloud boundary heights, i.e., cloud base height and cloud top height, based on Millimeter Cloud Radar 

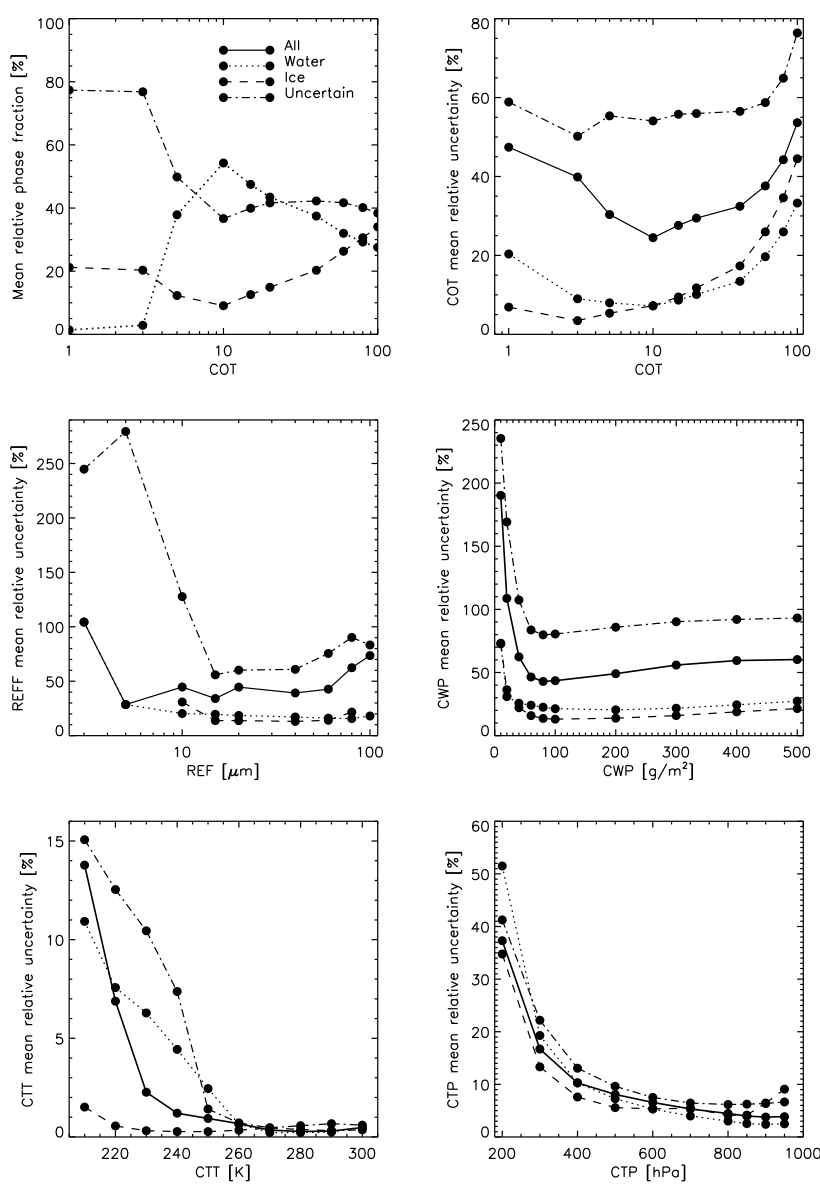

Figure 6. Histograms of the mean relative phase fraction and mean relative uncertainty estimates for FAME-C cloud properties cloud optical thickness (COT), effective radius (REF), cloud water path (CWP), cloud top temperature (CTT) and cloud top pressure (CTP) for all successfully retrieved cloudy pixels (converged and cost $<20$ ) for orbit segments covering the region in Germany between lat. 9 and $14^{\circ}$ and long. 49 and $54^{\circ}$ (presented in Fig. 5 as GER) for the years 2007-2009. Results are shown separately for the three cloud phases - water, ice and uncertain - and for all cloudy pixels.

(MMCR) and Micropulse Lidar (MPL) data (Clothiaux et al., 2000). The cloud boundaries are provided at a vertical resolution of $45 \mathrm{~m}$, a temporal resolution of $10 \mathrm{~s}$, and for up to 10 cloud layers.

For the comparison the dates and times of the Envisat overpasses at each ARM site are determined. For each overpass, the mean and standard deviation of both FAME-C cloud top height products are computed for a $9 \times 9$ pixel box centered around the pixel that matches best with the ARM site latitude and longitude values. Before doing so, parallax correction was performed for cloudy pixels. The mean ARSCL cloud top height is computed from cloud top heights within a $5 \mathrm{~min}$ period centered at the Envisat overpass time. Here, the ARSCL cloud top height is defined as the height of the highest cloud layer. The cases were selected based on the following three criteria. First, at least $75 \%$ of the pixels in the FAMEC $9 \times 9$ pixel box show a successful cloud top height retrieval for either AATSR or MERIS measurements. Second, for all time steps within the 5 min period, an ARSCL cloud top height is determined by the MMCR. Third, the standard deviation of both FAME-C and ARSCL cloud top heights is less than $1 \mathrm{~km}$. This results in 115 cases for AATSR and 90 for MERIS. We assume this difference in cases between both FAME-C cloud top height retrievals to be partly related to the fact that at the moment the MERIS cloud top pressure retrieval tends to fail more often than the AATSR cloud top temperature retrieval. This is related to the use of the different cloud vertical extinction profiles derived from CloudSat data for different cloud types in the radiative transfer simulations used to create the MERIS LUT and leads to jumps in the LUT at the cloud type transitions. It is envisaged that this issue will be dealt with in future versions of FAME-C.

Figure 8 shows the comparison of AATSR and MERIS cloud top heights to the ARSCL cloud top heights for singlelayer and multilayer cloud cases. Single-layer clouds are defined as cases where at least $80 \%$ of the radar observations in the 5 min time period only show one cloud layer. Multilayer cloud cases are defined as cases in the ARSCL product where at least two cloud layers exist with a minimum distance of $1 \mathrm{~km}$ between the cloud top height of the lower cloud layer and the cloud base height of the upper cloud layer, for at least $80 \%$ of the radar observations in the 5 min time period.

For single-layer clouds there is an overall small negative bias of $-0.3 \mathrm{~km}$ found between AATSR and ARSCL cloud top heights. Taking into account only the single-layer cloud cases with ARSCL cloud top heights larger than $3.5 \mathrm{~km}$, i.e., the mid-level and high-level clouds, the bias is $-1.1 \mathrm{~km}$ with an RMSD of $1.9 \mathrm{~km}$. This negative bias falls within the expected range of a few kilometers, since the retrieved cloud top temperature is rather the temperature at a height of 1 or more optical depths into the cloud. The cloud top height computed from the retrieved cloud top temperature therefore represents the radiometric height. Even for deep convective clouds, the IR radiometric height may lie a few kilometers below the physical cloud top (Sherwood et al., 2004). Minnis et al. (2008) found for optically thick ice clouds that the difference in IR radiometric height and cloud top heights derived from CALIOP data depends on the ice water content and its vertical profile, i.e., cloud vertical extinction profile, at the top of the cloud. For the single-layer clouds below $3.5 \mathrm{~km}$, the bias is $0.7 \mathrm{~km}$ with an RMSD of $1.3 \mathrm{~km}$. An overestimation of cloud top height for low-level clouds can occur in cases where the cloud top temperature is assigned to the wrong height level or temperature inversions that are not represented accurately in the modeled temperature profiles.

The overall positive bias of $0.5 \mathrm{~km}$ between MERIS and ARSCL cloud top heights for single-layer clouds can be mainly attributed to cases with mid-level and high-level clouds. For those clouds the variability is also large, with an RMSD of $2.8 \mathrm{~km}$ for cases with ARSCL cloud top heights 

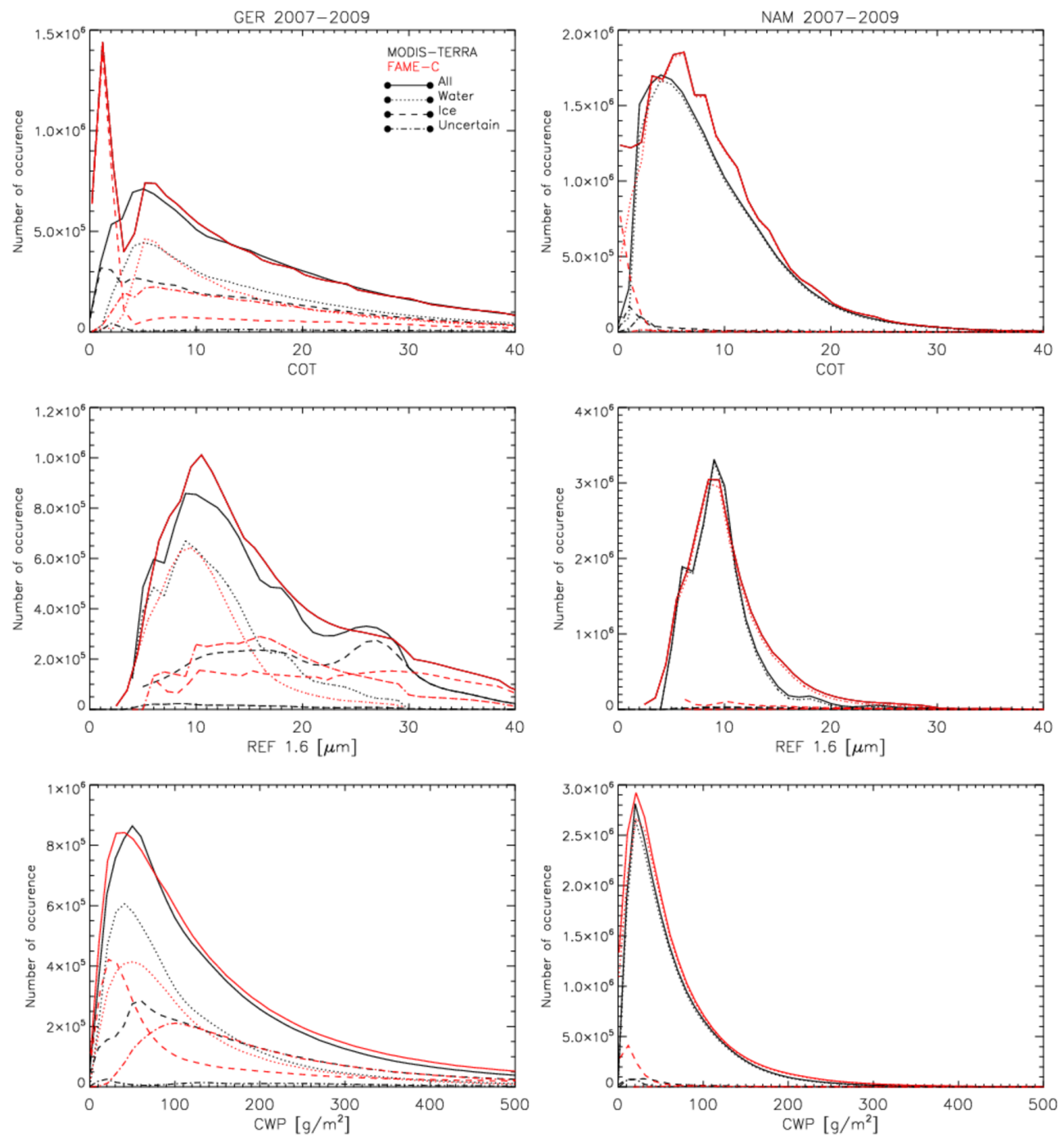

Figure 7. Frequency histograms of the pixel-based retrieved cloud optical and microphysical properties* of FAME-C and MODIS-Terra for the GER and NAM regions as presented in Fig. 5. ${ }^{*}$ Cloud optical thickness (COT), effective radius using channel 1.6 $\mu \mathrm{m}$ (REF16) and cloud water path (CWP).

larger than $3.5 \mathrm{~km}$. On the one hand, this shows that, by introducing the inhomogeneous cloud vertical extinction profiles for nine cloud types in the MERIS cloud top pressure retrieval, the large positive/negative bias found for cloud top pressures/cloud top heights retrievals assuming homogeneous cloud vertical extinction profiles appears to be eliminated. On the other hand, large scatter is introduced, since large variability exists in real cloud vertical extinction profiles. An underestimation/overestimation of MERIS cloud top pressures/cloud top heights may occur due to the fact that the radar on CloudSat does not detect small ice particles, therefore leading to an underestimation of extinction in upper cloud layers in the nine computed average extinction profiles. For low-level clouds, variability and bias are generally small. For both AATSR and MERIS single-layer cloud cases it is not evident to see that differences in cloud top heights between FAME-C and ARSCL is larger for optically thin clouds (mean cloud optical thickness $<8$ ) than for optically thick clouds.

Both MERIS and AATSR cloud top heights for multilayer clouds show higher biases and RMSDs, and lower correlations than the cloud top heights for single-layer clouds. A few cases showing large deviations are identified as cases where there is a minimum distance of $5 \mathrm{~km}$ (mlc distance $>5$ ) between two cloud layers, possibly representing high, thin cirrus clouds overlying a low-level water cloud. In those cases the retrieved cloud top height is expected to be below the height of the upper cloud layer. Interestingly, the MERIS cloud top heights show a smaller negative bias than the AATSR cloud top heights, though the RMSD is high and the number of cases is relatively small. Due to in-cloud scattering of photons in the visible channels and mainly absorption 

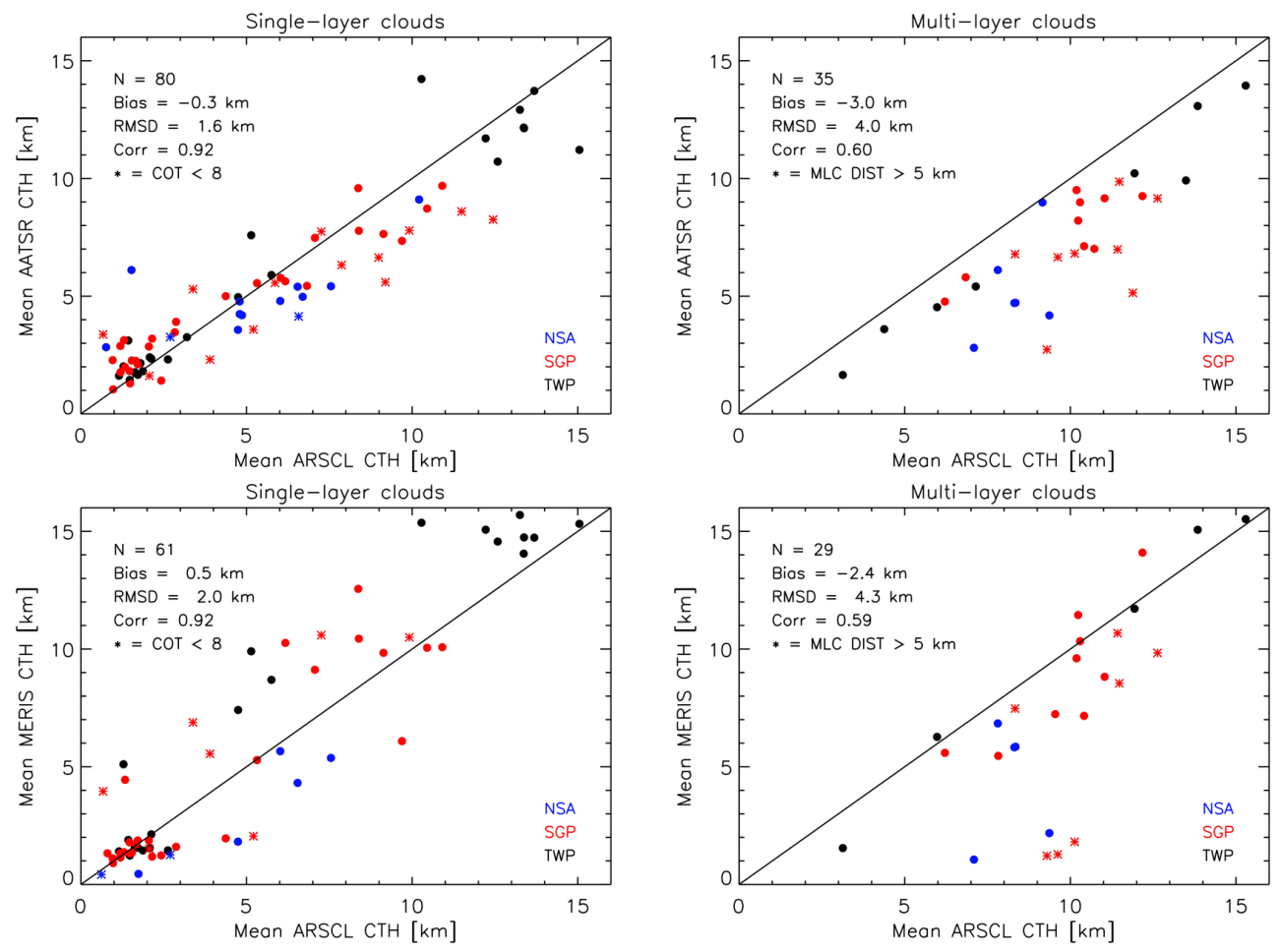

Figure 8. Results of the comparison of AATSR (top) and MERIS (bottom) mean cloud top height products with mean cloud top heights derived from radar observations at ARM sites for single-layer clouds (left) and multilayer clouds (right). For FAME-C the mean was computed from a $9 \times 9$ pixel box; for radar the mean was computed from all selected observations within a 5 min time period centered at the Envisat overpass time.

of photons in the IR channels, the AATSR cloud top height is expected to be closer to the height of the upper cloud than the MERIS cloud top height. An in-depth study is needed to assess the differences in AATSR and MERIS cloud top height retrievals in multilayer cloud cases and cases with vertically extended clouds.

\section{Summary and discussion}

This paper is intended to serve as a reference paper for the FAME-C algorithm, which is used to retrieve daytime cloud optical and microphysical properties and macrophysical properties and their uncertainties on a pixel basis. The AATSR and MERIS observations and accompanying forward models are presented as well as the auxiliary data used in FAME-C. As part of the preprocessing, AATSR and MERIS observations are collocated and cloud screening is performed using all channels from both instruments. Next, for all cloudy pixels, a simple cloud phase detection is performed. The retrieval scheme itself consists of two main steps and is carried out on a pixel basis for those pixels identified as cloudy by the cloud mask. First, the cloud optical and microphysical property retrieval is performed using an AATSR visible and near-infrared channel, resulting in retrieved cloud optical thickness and effective radius. From those, cloud wa- ter path is also computed. Separate forward models have been developed for water and ice clouds. Second, the cloud top height retrievals are performed using observations from AATSR thermal infrared channels for the cloud top temperature retrieval and observations from the MERIS oxygen-A absorption channel for the cloud top pressure retrieval. The MERIS cloud top pressure retrieval in particular depends on the assumed vertical extinction profile of the cloud. Therefore, in both cloud top height retrievals, vertically inhomogeneous cloud profiles are assumed derived from 1 year of CloudSat data. The cloud optical thickness previously retrieved serves as input for both cloud top height retrievals.

The use of the optimal estimation method in the retrieval scheme allows for a propagation of a priori knowledge, as well as the uncertainty estimates of the measurements and forward model parameters, into the final retrieval of the cloud property and its uncertainty. At this point, the contribution of the a priori estimate in FAME-C to the retrieved state and its uncertainty is negligible. Estimates of uncertainties in the measurements and forward model parameters are shown. Both the inclusion of independent a priori knowledge and a more extended uncertainty estimate budget and assessment are envisaged in the future to fully exploit the advantages of the optimal estimation method. 
A comparison to MODIS-Terra monthly means derived from level-2 cloud products for four selected regions was performed for cloud fraction, cloud phase, and the cloud optical and microphysical properties. Results show an overall good agreement between FAME-C and MODIS cloud optical and microphysical properties. Differences become larger when looking at biases and RMSDs for one specific cloud phase. The comparison of the FAME-C cloud top height products and cloud top heights derived from a ground-based cloud radar reveal an underestimation of FAME-C cloud top height, except for AATSR cloud top heights for low-level singlelayer clouds and MERIS cloud top heights for mid-level and high-level single-layer clouds. For single-layer clouds, variability is clearly higher for mid-level and high-level clouds than for low-level clouds. The bias and RMSD are higher for multilayer clouds than for single-layer clouds, while correlation is clearly lower. For in-depth FAME-C cloud top height retrieval evaluations, the comparisons will be extended to CloudSat and CALIPSO observations of cloud top heights for scenes where Envisat and A-train have overlapping overflights.

Ongoing FAME-C retrieval developments and verifications, taking place within phase 2 of the ESA Climate Change Initiative Cloud project, focus on a more advanced cloud phase retrieval, improved cirrus cloud detection and a separate forward model for multilayer cloud situations. One of the main topics of interest will be the exploitation of the difference in sensitivity of the independent AATSR and MERIS cloud top height retrievals to distinct cloud layers and relating these differences in retrieved cloud top heights to cloud vertical inhomogeneities. Furthermore, it is planned that FAME-C will be adapted to retrieve all cloud properties at once, resulting in a physically more consistent retrieval. Further ongoing work includes verification efforts on larger spatial scales, comparisons of seasonal and interannual variations, and comparisons to other satellite-derived cloud properties as well as cloud properties derived from ground-based observations.

Acknowledgements. The authors would like to thank the ESA for providing the funding for this study in the framework of the CCI project, as well as the Bundesministerium für Bildung und Forschung for providing funding in the framework of the $\mathrm{HD}(\mathrm{CP})^{2}$ project. Furthermore, authors would also like to thank Andi Walther for fruitful discussions and for providing the MODTRAN-based AATSR atmospheric absorption coefficients, and Martin Stengel for help with the ERA-Interim data. Lastly, the authors would also like to thank NASA-LAADS for providing the MODIS-Terra cloud products and the Atmospheric Radiation Measurement (ARM) program sponsored by the US Department of Energy for providing the ARSCL products.

Edited by: B. Mayer

\section{References}

Baum, B. A., Yang, P., Heymsfield, A. J., Platnick, S., King, M. D., $\mathrm{Hu}$, Y., and Bedka, S. T.: Bulk scattering properties for the remote sensing of ice clouds. Part II: Narrowband models, J. Appl. Meteorol., 44, 1896-1911, 2005.

Bennartz, R. and Fischer, J.: A modified $k$-distribution approach applied to narrow band water vapour and oxygen absorption estimates in the near infrared, J. Quant. Spectrosc. Ra., 66, 539-553, 2000.

Bourg, L., D'Alba, L., and Colagrande, P.: MERIS Smile effect characterisation and correction, European Space Agency, Paris, Technical note, http://earth.esa.int/pcs/envisat/meris/ documentation/MERIS_Smile_Effect.pdf (last access: November 2014), 2008.

Chen, Y., Sun-Mack, S., Minnis, P., Smith, W. L., and Yooung, D. F.: Surface spectral emissivity derived from MODIS data, in: Optical Remote Sensing of the Atmosphere and Clouds III, vol. 361 of Proc. SPIE 4891, doi:10.1117/12.465995, 2003.

Chen, Y., Sun-Mack, S., Arduini, R. F., and Minnis, P.: Clear-sky and surface narrowband albedo variations derived from VIRS and MODIS Data, in: CONFERENCE ON CLOUD PHYSICS, CD ROM EDITION, 5.6 Atmospheric radiation 12th, Conference, Atmospheric radiation, vol. 12, Atmospheric radiation, Boston, Mass., USA, 2006.

Clothiaux, E. E., Ackerman, T. P., Mace, G. G., Moran, K. P., Marchand, R. T., Miller, M. A., and Martner, B. E.: Objective determination of cloud heights and radar reflectivities using a combination of active remote sensors at the ARM CART sites, J. Appl. Meteorol., 39, 645-665, 2000.

Doppler, L., Preusker, R., Bennartz, R., and Fischer, J.: $k$-bin and $k$ IR: $k$-distribution methods without correlation approximation for non-fixed instrument response function and extension to the thermal infrared - Applications to satellite remote sensing, J. Quant. Spectrosc. Ra., 133, 382-395, 2014.

ESA: MERIS Quality Working Group: MERIS 3rd data reprocessing, Software and ADF updates, Tech. Rep. A879.NT.008.ACRIST, ACRI, Technical report, ESA, http://earth.eo.esa.int/pcs/ envisat/meris/documentation/ (last access: May 2014), 2011.

ESA: BEAM Earth Observation Toolbox and Development Platform, The BEAM Project, http://www.brockmann-consult.de/ $\mathrm{cms} / \mathrm{web} /$ beam, last access: May 2014a.

ESA: AATSR Handbook, section "Pre-flight characteristics and expected performance", https://earth.esa.int/handbooks/ aatsr/CNTR3-2-1.htm, last access: May 2014b.

ESA: ESA bulletin 105 February 2001; AATSR: Global-Change and Surface-Temperature Measurements from Envisat, http: //www.esa.int/esapub/bulletin/bullet105/bul105_1.pdf, last access: May 2014c.

ESA: SENTINEL-3 Copernicus, http://www.esa.int/Our_ Activities/Observing_the_Earth/Coperni\%cus/Sentinel-3, last access: May 2014d.

Fell, F. and Fischer, J.: Numerical simulation of the light field in the atmosphere-ocean system using the matrix-operator method, J. Quant. Spectrosc. Ra., 69, 351-388, 2001.

Fomferra, N. and Brockmann, C.: Beam-the ENVISAT MERIS and AATSR toolbox, in: MERIS (A) ATSR Workshop 2005, vol. 597, p. 13, 2005.

Gómez-Chova, L., Camps-Valls, G., Munoz-Marı, J., Calpe, J., and Moreno, J.: Cloud screening methodology for MERIS/AATSR 
Synergy products, in: Proc. 2nd MERIS/AATSR User Workshop, ESRIN, Frascati, 22-26, 2008.

Gómez-Chova, L., Camps-Valls, G., Calpe, J., Munoz, J., and Moreno, J.: Cloud Screening ATBD, Algorithm theoretical basis document, University of Valencia, Burjassot-Valencia, 2010.

Hall, D. K., Salomonson, V. V., and Riggs., G. A.: MODIS/Aqua Snow Cover Monthly L3 Global 0.05Deg CMG. Version 5, [2007-2009], available at: http://nsidc.org/data/myd10cm.html (last access: November 2014), 2006.

Hamann, U., Walther, A., Baum, B., Bennartz, R., Bugliaro, L., Derrien, M., Francis, P. N., Heidinger, A., Joro, S., Kniffka, A., Le Gléau, H., Lockhoff, M., Lutz, H.-J., Meirink, J. F., Minnis, P., Palikonda, R., Roebeling, R., Thoss, A., Platnick, S., Watts, P., and Wind, G.: Remote sensing of cloud top pressure/height from SEVIRI: analysis of ten current retrieval algorithms, Atmos. Meas. Tech., 7, 2839-2867, doi:10.5194/amt-7-2839-2014, 2014.

Hansen, J. E. and Hovenier, J.: Interpretation of the polarization of Venus, J. Atmos. Sci, 31, 1137-1160, 1974.

Hansen, J. E. and Travis, L. D.: Light scattering in planetary atmospheres, Space Sci. Rev., 16, 527-610, 1974.

Henken, C. C., Lindstrot, R., Filipitsch, F., Walther, A., Preusker, R., and Fischer, J.: FAME-C: Retrieval of cloud top pressure with vertically inhomogeneous cloud profiles, in: AIP Conference Proceedings, vol. 1531, p. 412, 2013.

Heymsfield, A. J., Matrosov, S., and Baum, B.: Ice water pathoptical depth relationships for cirrus and deep stratiform ice cloud layers, J. Appl. Meteorol., 42, 1369-1390, 2003.

Hollmann, R., Merchant, C. J., Saunders, R., Downy, C., Buchwitz, M., Cazenave, A., Chuvieco, E., Defourny, P., de Leeuw, G., Forsberg, R., Holzer-Popp, T., Paul, F., Sandven, S., Sathyendranath, S., van Roozendael, M., and Wagner, W.: The ESA climate change initiative: Satellite data records for essential climate variables, B. Am. Meteorol. Soc., 94, 1541-1552, 2013.

Hollstein, A. and Fischer, J.: Radiative transfer solutions for coupled atmosphere ocean systems using the matrix operator technique, J. Quant. Spectrosc. Ra., 113, 536-548, 2012.

IPCC: IPCC, 2013: Summary for Policymakers, in: Climate Change 2013: The Physical Science Basis., Tech. rep., 2013.

Schiffer, R. A. and Rossow, W. B.: The International Satellite Cloud Climatology Project (ISCCP): The First Project of the World Climate Research Programme, B. Am. Meteorol. Soc., 64, 779-784, 1983.

Lindstrot, R., Preusker, R., and Fischer, J.: Empirical Correction of Stray Light within the MERIS Oxygen A-Band Channel, J. Atmos. Ocean. Tech., 27, 1185-1194, 2010.

Llewellyn-Jones, D., Edwards, M., Mutlow, C., Birks, A., Barton, I., and Tait, H.: AATSR: Global-change and surface-temperature measurements from Envisat, ESA Bull., 105, 11-21, 2001.

McClatchey, R. A., Fenn, R., Selby, J. A., Volz, F., and Garing, J.: Optical properties of the atmosphere, Tech. rep., DTIC Document, 1972.

METOffice: RTTOV: RTTOV v9 resources, http://nwpsaf.eu/ deliverables/rtm/rtm_rttov9.html, last access: November 2014.

Minnis, P., Liou, K.-N., and Takano, Y.: Inference of cirrus cloud properties using satellite-observed visible and infrared radiances. Part I: Parameterization of radiance fields, J. Atmos. Sci., 50, 1279-1304, 1993.
Minnis, P., Garber, D. P., Young, D. F., Arduini, R. F., and Takano, Y.: Parameterizations of reflectance and effective emittance for satellite remote sensing of cloud properties, J. Atmos. Sci., 55, 3313-3339, 1998.

Minnis, P., Yost, C. R., Sun-Mack, S., and Chen, Y.: Estimating the top altitude of optically thick ice clouds from thermal infrared satellite observations using CALIPSO data, Geophys. Res. Lett., 35, L12801, doi:10.1029/2008GL033947, 2008.

Minnis, P., Sun-Mack, S., Young, D. F., Heck, P. W., Garber, D. P., Chen, Y., Spangenberg, D. A., Arduini, R. F., Trepte, Q. Z., Smith, W. L., Ayers, J. K., Gibson, S. C., Miller, W. F., Chakrapani, V., Takano, Y., Liou, K.-N., Xie, Y., and Yang, P.: CERES edition-2 cloud property retrievals using TRMM VIRS and Terra and Aqua MODIS data - Part I: Algorithms, IEEE T. Geosci. Remote, 49, 4374-4400, 2011.

Muller, J.-P., Preusker, R., Fischer, J., Zuhlke, M., Brockmann, C., and Regner, P.: ALBEDOMAP: MERIS land surface albedo retrieval using data fusion with MODIS BRDF and its validation using contemporaneous EO and in situ data products, in: Geoscience and Remote Sensing Symposium, 2007, IGARSS, 2007, IEEE International, 2404-2407, 2007.

Nakajima, T. and King, M. D.: Determination of the optical thickness and effective particle radius of clouds from reflected solar radiation measurements. Part I: Theory, J. Atmos. Sci., 47, 1878-1893, 1990.

Nakajima, T. Y. and Nakajma, T.: Wide-area determination of cloud microphysical properties from NOAA AVHRR measurements for FIRE and ASTEX regions, J. Atmos. Sci., 52, 4043-4059, 1995.

NASA: MODIS CERES Science Team, Clouds and the Earth's Radiant Energy System, http://ceres.larc.nasa.gov/, last access: May 2014a.

NASA: MODIS Science Team, Atmosphere, Cloud, http:// modis-atmos.gsfc.nasa.gov/MOD06_L2/index.html, last access: May 2014b.

NASA Land Processes Distributed Active Archive Center (LP DAAC), Sioux Falls, S. D. U.: MODIS/Terra+Aqua Albedo 16-Day L3 Global 0.05Deg CMG, Version 5., available at: https: //lpdaac.usgs.gov/ (last access: November 2014), 2007-2009.

AVHRR Cloud Properties -PATMOS-x (DCOMP) -Climate Algorithm Theoretical Basis Document, NOAA Climate Data Record Program CDRP-ATBD-0523 by CDRP Document Manager Rev. 1, available at: http://www.ncdc.noaa.gov/cdr/operationalcdrs. html, 2014.

Pawlowska, H. and Brenguier, J.-L.: Microphysical properties of stratocumulus clouds during ACE-2, Tellus B, 52, 868-887, 2000.

Preusker, R. and Lindstrot, R.: Remote Sensing of Cloud-Top Pressure Using Moderately Resolved Measurements within the Oxygen A Band-A Sensitivity Study, J. Appl. Meteorol. Clim., 48, 1562-1574, 2009.

Pruppacher, H. R. and Klett, J. D.: Microphysics of Clouds and Precipitation, 2nd Edn., Kluwer Academic Publishers, 1997.

Rast, M., Bezy, J., and Bruzzi, S.: The ESA Medium Resolution Imaging Spectrometer MERIS a review of the instrument and its mission, Int. J. Remote Sens., 20, 1681-1702, 1999.

Rodgers, C. D.: Inverse methods for atmospheric sounding: Theory and Practice, Series on Atmospheric, Oceanic and Planetary Physics, Vol. 2, 2000. 
Roebeling, R., Feijt, A., and Stammes, P.: Cloud property retrievals for climate monitoring: Implications of differences between Spinning Enhanced Visible and Infrared Imager (SEVIRI) on METEOSAT-8 and Advanced Very High Resolution Radiometer (AVHRR) on NOAA-17, J. Geophys. Res.-Atmos., 111, D20210, doi:10.1029/2005JD006990, 2006.

Roebeling, R., Baum, B., Bennartz, R., Hamann, U., Heidinger, A., Thoss, A., and Walther, A.: Evaluating and Improving Cloud Parameter Retrievals, B. Am. Meteorol. Soc., 94, ES41-ES44, 2013.

Rothman, L. S., Gordon, I. E., Barbe, A., Chris Benner, D., Bernath, P. F., Birk, M., Boudon, V., Brown, L. R., Campargue, A., Champion, J.-P., Chance, K., Coudert, L. H., Dana, V., Devi, V. M., Fally, S., Flaud, J.-M., Gamache, R. R., Goldman, A., Jacquemart, D., Kleiner, I., Lacome, N., Lafferty, W. J., Mandinj, J.-Y., Massie, S. T., Mikhailenko, S. N., Miller, C. E., Moazzen-Ahmadi, N., Naumenko, O. V., Nikitin, A. V., Orphal, J., Perevalov, V. I., Perrin, A., Predoi-Cross, A., Rinslandt, C. P., Rotger, M., Šimecková, M., Smitht, M. A. H., Sung, K., Tashkun, S. A., Tennyson, J., Toth, R. A., Vandaele, A. C., and Vander Auwera, J.: The HITRAN 2008 molecular spectroscopic database, J. Quant. Spectrosc. Ra., 110, 533-572, 2009.

Saunders, R. and Kriebel, K.: An improved method for detecting clear sky and cloudy radiances from AVHRR data, Int. J. Remote Sens., 9, 123-150, 1988.

Saunders, R., Matricardi, M., and Geer, A.: RTTOV-9 Users Guide, NWP SAF Rep. NWPSAF-MO-UD-016, User guide, Met Office, 2010.

Sayer, A. M., Poulsen, C. A., Arnold, C., Campmany, E., Dean, S., Ewen, G. B. L., Grainger, R. G., Lawrence, B. N., Siddans, R., Thomas, G. E., and Watts, P. D.: Global retrieval of ATSR cloud parameters and evaluation (GRAPE): dataset assessment, Atmos. Chem. Phys., 11, 3913-3936, doi:10.5194/acp-11-39132011, 2011.
Seemann, S. W., Borbas, E. E., Knuteson, R. O., Stephenson, G. R., and Huang, H.-L.: Development of a global infrared land surface emissivity database for application to clear sky sounding retrievals from multispectral satellite radiance measurements, J. Appl. Meteorol. Clim., 47, 108-123, 2008.

Sherwood, S. C., Chae, J.-H., Minnis, P., and McGill, M.: Underestimation of deep convective cloud tops by thermal imagery, Geophys. Res. Lett., 31, L11102, doi:10.1029/2004GL019699, 2004.

Smith, D., Poulsen, C., and Latter, B.: Calibration status of the AATSR reflectance channels, in: Proceedings of the MERIS/AATSR Workshop, 2008.

Stubenrauch, C. J., Rossow, W. B., Kinne, S., Ackerman, S., Cesana, G., Chepfer, H., Di Girolamo, L., Getzewich, B., Guignard, A., Heidinger, A., Maddux, B. C., Menzel, W. P., Minnis, P., Pearl, C., Platnick, S., Poulsen, C., Riedi, J., Sun-Mack, S., Walther, A., Winker, D., Zeng, S., and Zhao, G.: Assessment of global cloud datasets from satellites: Project and database initiated by the GEWEX Radiation Panel, B. Am. Meteorol. Soc., 94, 1031-1049, 2013.

Walther, A. and Heidinger, A. K.: Implementation of the daytime cloud optical and microphysical properties algorithm (DCOMP) in PATMOS-x, J. Appl. Meteorol. Clim., 51, 1371-1390, 2012.

Wang, M. and King, M. D.: Correction of Rayleigh scattering effects in cloud optical thickness retrievals, J. Geophys. Res., 102, 25915-25926, doi:10.1029/97JD02225, 1997.

Wiscombe, W. J.: Improved Mie scattering algorithms, Appl. Optics, 19, 1505-1509, 1980.

Zhang, Z., Ackerman, A. S., Feingold, G., Platnick, S., Pincus, R., and Xue, H.: Effects of cloud horizontal inhomogeneity and drizzle on remote sensing of cloud droplet effective radius: Case studies based on large-eddy simulations, J. Geophys. Res.Atmos., 117, D19208, doi:10.1029/2012JD017655, 2012. 